\title{
Abundance estimates and trends for humpback whales (Megaptera novaeangliae) in Antarctic Areas IV and V based on JARPA sightings data
}

\author{
Koji Matsuoka, Takashi Hakamada, Hiroshi Kiwada, Hiroto Murase and Shigetoshi Nishiwaki \\ The Institute of Cetacean Research, 4-5, Toyomi-cho, Chuo-ku, Tokyo 104-0055, Japan \\ Contacte-mail: matsuoka@cetacean.jp
}

\begin{abstract}
Sighting survey data from the Japanese Whale Research Program under Special Permit in the Antarctic (JARPA) are analysed to obtain abundance estimates for humpback whales (Megaptera novaeangliae) south of $60^{\circ} \mathrm{S}$. The surveys were conducted during the $1989 / 90-2004 / 05$ austral summer seasons (mainly in January and February); the survey areas alternated between Area IV $\left(70^{\circ} \mathrm{E}-130^{\circ} \mathrm{E}\right)$ and $\mathrm{Area} \mathrm{V}\left(130^{\circ} \mathrm{E}\right.$ to $\left.170^{\circ} \mathrm{W}\right)$ each year. Primary sighting effort totalled 293,811 n.miles over 6,188 days. Abundance estimates are obtained using standard line transect analysis methods and the program DISTANCE. Estimated densities of humpback whales were highest east of the Kerguelen Plateau $\left(80^{\circ} \mathrm{E}-120^{\circ} \mathrm{E}\right)$. Abundance estimates for Area IV range from 2,747 (CV = 0.153) in 1993/94 to 31,134 (CV=0.123) in 2001/02, while those for Area V range from $602(\mathrm{CV}$ $=0.343)$ in $1990 / 91$ to $9,342(\mathrm{CV}=0.337)$ in $2004 / 05$. The estimates are similar to those obtained from the International Whaling Commission's IDCR-SOWER surveys, which were conducted in Area IV (in 1978/79, 1988/89 and 1998/99) and in Area V (in 1980/81, 1991/92 and 2001/022003/04). Estimated annual rates of increase for Area IV $(16.4 \% ; 95 \% \mathrm{CI}=9.5-23.3 \%)$ and Area V $(12.1 \% ; 95 \% \mathrm{CI}=1.7-22.6 \%)$ are also similar to those obtained from the IDCR-SOWER surveys. The total abundance in Areas IV and V based on the most recent JARPA surveys (2003/04 and $2004 / 05$ combined) is $37,125(95 \% \mathrm{CI}=21,349-64,558)$; the confidence interval incorporates estimated additional variance. Results of several sensitivity tests are presented that suggest that estimates of abundance and trends are not appreciably affected by factors such as different approaches to deal with survey coverage (which in some cases was poor or included gaps). Changes in the order in which survey strata were covered and potential effects are investigated using a nested GLM approach; a QAIC model selection criterion suggests a preference for not attempting to adjust for such changes. Under various sensitivity approaches, the point estimates of increase rates are not greatly affected for Area IV. Although they drop by typically a half for most approaches for Area V, they nevertheless remain within the confidence limits of the base case estimate of $12.1 \%$ per year $(95 \% \mathrm{CI}=1.7-22.6 \%)$. The presented results thus suggest that the estimated abundance of humpback whales in Area IV has increased rapidly. Although there is also an increase indicated for Area V, it is neither as rapid nor as precisely estimated. Taking these results together with the similar rates of increase estimated from coastal surveys off western and eastern Australia for Breeding Stocks D and E respectively, and given demographic limitations on the increase rates possible for closed populations of humpback whales, the hypothesis is advanced that whales from Breeding Stock E may have shifted their feeding distribution westward as their numbers have increased, perhaps to take advantage of the higher densities of krill to be found to the west.
\end{abstract}

KEYWORDS: ABUNDANCE ESTIMATE; ANTARCTIC; HUMPBACK WHALE; JARPA; SURVEY-VESSEL; TRENDS

\section{INTRODUCTION}

There are several genetic stocks (genetically differentiated populations within a species) of humpback whales in the Southern Hemisphere. The International Whaling Commission Scientific Committee (IWC SC) has hypothesised a total of at least seven Breeding Stocks, which it has called Stocks 'A', 'B', ... 'G' (IWC, 2005) and is still working to refine this. The population named Breeding Stock $\mathrm{D}$ has its breeding grounds in the waters off western Australia and in summer is believed to be found mainly in Area IV, south of $60^{\circ} \mathrm{S}$. Breeding Stock E which has its breeding grounds in the waters off eastern Australia and some of the south Pacific islands, is believed to be found mainly in Area V south of $60^{\circ} \mathrm{S}$ in summer.

Humpback whales were heavily over-exploited during the last century. Allen (1980) estimated that at the end of commercial whaling, the stocks of this species had been reduced to $2 \%$ of an original population of 130,000 animals. More recent evaluations as part of the IWC Scientific Committee's Comprehensive Assessment are ongoing, but results reported to date, when summed over the seven Breeding Stocks, suggest an original abundance of about 125,000 whales reduced to a minimum of about $4 \%$ of that number by the mid-1960s (e.g. IWC, 2009; Jackson et al., 2008; Johnston et al., 2011; Johnston and Butterworth, 2005; Johnston and Butterworth, 2007; Zerbini et al., 2011). Fortunately, signs of recovery are now evident for many, although not all, of these stocks. In particular, the abundance of Breeding Stocks D and E have been estimated, based on data from off Australia, to be increasing at annual rates of around $10 \%-10.2 \%, \mathrm{SE}=4.6 \%$ by Bannister and Hedley (2001) and at $10.6 \%, \mathrm{SE}=0.5 \%$ by Noad et al., (2011). In addition to the conservation value for continued monitoring of the abundance and trends of these stocks, continued monitoring is also important because the stocks provide an excellent opportunity to improve understanding of the dynamics of baleen whale populations recovering from low levels.

There are two major sources of systematic sightings data in the Antarctic; one of these is the IWCs IDCR/SOWER cruises (e.g. see Matsuoka et al., 2001), which are considered later in this paper. The other and the focus of the present paper, is the sighting component of the JARPA (Japanese Whale Research Program under Special Permit in the Antarctic) programme. The stated objectives of the JARPA programme were: (a) elucidation of the stock structure of the Antarctic minke whale (Balaenoptera bonaerensis) to improve stock management; (b) estimation of biological parameters of the Antarctic minke whale to improve the stock management; (c) elucidation of the role of whales in the Antarctic marine ecosystem through whale feeding ecology; and (d) elucidation of the effect of environmental change on cetaceans (Government of Japan, 1987; 1996). In order to address these four objectives, JARPA comprised a combination of sighting and lethal sampling surveys. This programme took place each year from $1987 / 88$ to $2004 / 05$ 
during the austral summer. JARPA was designed to alternate surveys in Antarctic Areas IV and V in each of the sixteen years of the full-scale research period.

Sightings data collected by the SVs (dedicated sighting vessels) and SSVs (sighting and sampling vessels) during JARPA have been used to estimate abundance and abundance trends of blue whales (Branch et al., 2004) and other large whale species (Kasamatsu et al., 2000; Matsuoka et al., 2005a; Matsuoka et al., 2005b). Abundance estimates for Antarctic minke and humpback whales have also been presented to annual and intersessional meetings of the IWC Scientific Committee (e.g. Hakamada et al., 2006; Matsuoka et al., 2006) including the recent review of the JARPA programme (IWC, 2008). During these meetings, concerns were expressed on certain aspects of the work, particularly the potential effect of the sampling component (of Antarctic minke whales) of the JARPA surveys on the abundance estimates of this and other species of whales (e.g. Wade, 2008). The review Workshop recommended further work and made a number of specific suggestions (Table 1).

The primary objective of this paper is to present analyses of the humpback whale sightings data in Antarctic Areas IV and $\mathrm{V}$ that take into account relevant recommendations of the IWC Scientific Committee. To facilitate understanding of the estimation procedures and the interpretation of results, some details of the JARPA survey procedures are provided below, with further details set out in appendix 1 of Hakamada et al. (2007).

A secondary objective of this study is to compare JARPA abundance estimates in the feeding grounds of Areas IV and $\mathrm{V}$ with those in the breeding grounds and migratory corridors in the waters off both sides of Australia. (Bannister and Hedley, 2001; Paxton et al., 2011) and eastern Australia (Noad et al., 2011).

In addition, the paper will compare abundance estimates in Areas IV and V obtained by JARPA with those obtained by the IWCs IDCR (International Decade for Cetacean Research) and SOWER (Southern Ocean Whale and Ecosystem Research) research programmes. Under these programmes, dedicated sighting surveys (primarily aimed at Antarctic minke whales) have been conducted by the IWC in the Antarctic annually from $1978 / 79$ to $1995 / 96$ (IDCR) and then from 1996/97 (SOWER). An overview of IDCR/SOWER surveys is given in Matsuoka et al. (2003). One of the features of JARPA is that, unlike the IDCR/SOWER programmes, surveys have been repeated in the same area and in similar months every second season over a long period. The JARPA surveys can thus facilitate estimation of trends and the extent of inter-year variability in local abundance.

\section{SURVEY DESIGN AND DATA COLLECTION}

As noted above, JARPA comprised a combination of sighting and lethal sampling surveys. In order to try to obtain biological samples representative of the Antarctic minke whale population, a random sampling method was adopted within a line transect sighting survey design. The sighting and sampling surveys were conducted by two or three SSVs proceeding along predetermined tracklines. A dedicated SV was introduced from the 1991/92 season. The JARPA surveys have been conducted in a generally consistent way since 1989/90. This paper incorporates data from the eight full-scale surveys in Area IV (1989/90, 1991/92, 1993/94, 1995/96, 1997/98, 1999/00, 2001/02 and 2003/04), and the eight in Area V (1990/91, 1992/93, 1994/95, 1996/97, 1998/99, 2000/01, 2002/03 and 2004/05). Details of the surveys' design and some modifications over time are given in Nishiwaki et al. (2006) and in appendix 1 of Hakamada et al. (2007). Implications of some of these modifications for the results for abundance and abundance trends are discussed later.

\section{Research area}

The research area and geographical sub-divisions are shown in Fig. 1. Although JARPA covered the Antarctic sector between $35^{\circ} \mathrm{E}$ and $170^{\circ} \mathrm{W}$ south of $60^{\circ} \mathrm{S}$, the analyses in this paper focus on IWC management Areas IV $\left(70^{\circ} \mathrm{E}-130^{\circ} \mathrm{E}\right)$ and $\mathrm{V}\left(130^{\circ} \mathrm{E}-170^{\circ} \mathrm{W}\right)$ since this allows them to be restricted to data collected in the same months (January-February) over the full set of cruises. Areas IV and V were divided into two sectors (western and eastern) that were further divided into northern $\left(60^{\circ} \mathrm{S}\right.$ to 45 n.miles from the ice edge) and southern (from the ice edge to 45 n.miles away) strata. The western sector of Area IV includes a separate Prydz Bay stratum. For this sector, north and south strata were divided at $66^{\circ} \mathrm{S}$. The eastern sector of Area V includes the Ross Sea; for this sector the north and south strata were divided at $69^{\circ} \mathrm{S}$.

\section{Monthly coverage \\ Although the JARPA research period ranged from the end of November to March in each season, regular research in Areas IV and V was concentrated in January and February (Fig. 2). This coincides with the peak migration period of humpback whales to Antarctic feeding grounds (Kasamatsu et al., 1996).}

Table 1

List of recommendations for improvements to estimates of abundance of humpback whales from the JARPA surveys from the IWC Scientific Committee (IWC, 2008) and priority assigned by the Advisory Group.

\begin{tabular}{|c|c|c|}
\hline Tasks & Priority & Remarks \\
\hline $\begin{array}{l}\text { 1. Estimation of detection function (re-estimate in the cases where the } \\
\text { number of detection is small) }\end{array}$ & $\mathrm{H}$ & Addressed; Table 6a, 6b (Abundance); Table 7 (Trend) \\
\hline $\begin{array}{l}\text { 2. Investigation of sensitivities to pooling all vessels to estimate effective } \\
\text { strip width and mean school size }\end{array}$ & M & For humpback whales, data had already been pooled for all vessels \\
\hline 3. Variance estimation from the SSV data & M & To be addressed in future work \\
\hline 4. Sensitivity analysis with appropriate weighting and/or bootstrapping & M & Addressed; Tables $6 \mathrm{a}, 6 \mathrm{~b}$ and 7 \\
\hline $\begin{array}{l}\text { 5. Abundance estimates treating as if abundance in gaps between two } \\
\text { strata were } 0\end{array}$ & $\mathrm{~L}$ & Addressed; Table $6 \mathrm{a}, 6 \mathrm{~b}$ and 7 \\
\hline $\begin{array}{l}\text { 6. Extrapolation of density into unsurveyed areas } \\
\text { were surveyed }\end{array}$ & $\mathrm{H}$ & Addressed; Table 6a, \\
\hline 8. Estimation of additional variance & M & Partially addressed; Table 7 and 9b, Future analyses will utilize GLM \\
\hline $\begin{array}{l}\text { 9. Revised estimates of annual increase rate and its CV following } \\
\text { suggestions } 1-8\end{array}$ & M & Addressed; Table 7 and $9 \mathrm{~b}$ \\
\hline
\end{tabular}


Research vessels

Relevant information on the vessels used is given in Table 2. Kyo-maru No.1 (K01), Toshi-maru No.25 (T25) and Toshimaru No.18 (T18) operated as SSVs for the surveys from $1989 / 90$ to $1997 / 1998$. Kyosin-maru No.2 (KS2) engaged exclusively in sighting surveys (SV) from 1995/96. Yusinmaru (YS1) was used from the 1998/1999 cruise replacing the T18 and Yusin-maru No.2 (YS2) was used from the 2001/2002 cruise replacing the T25.

\section{Order of the surveys}

The order in which strata were surveyed within the main survey period (January-February) is shown in Figs $3 a$ and $3 b$ for Areas IV and $\mathrm{V}$ respectively. Abundance estimates are based on single coverage of the blocks shown in Fig. 3 in the season concerned.

\section{Trackline design}

The trackline was designed to cover the whole research area and was followed consistently throughout the JARPA
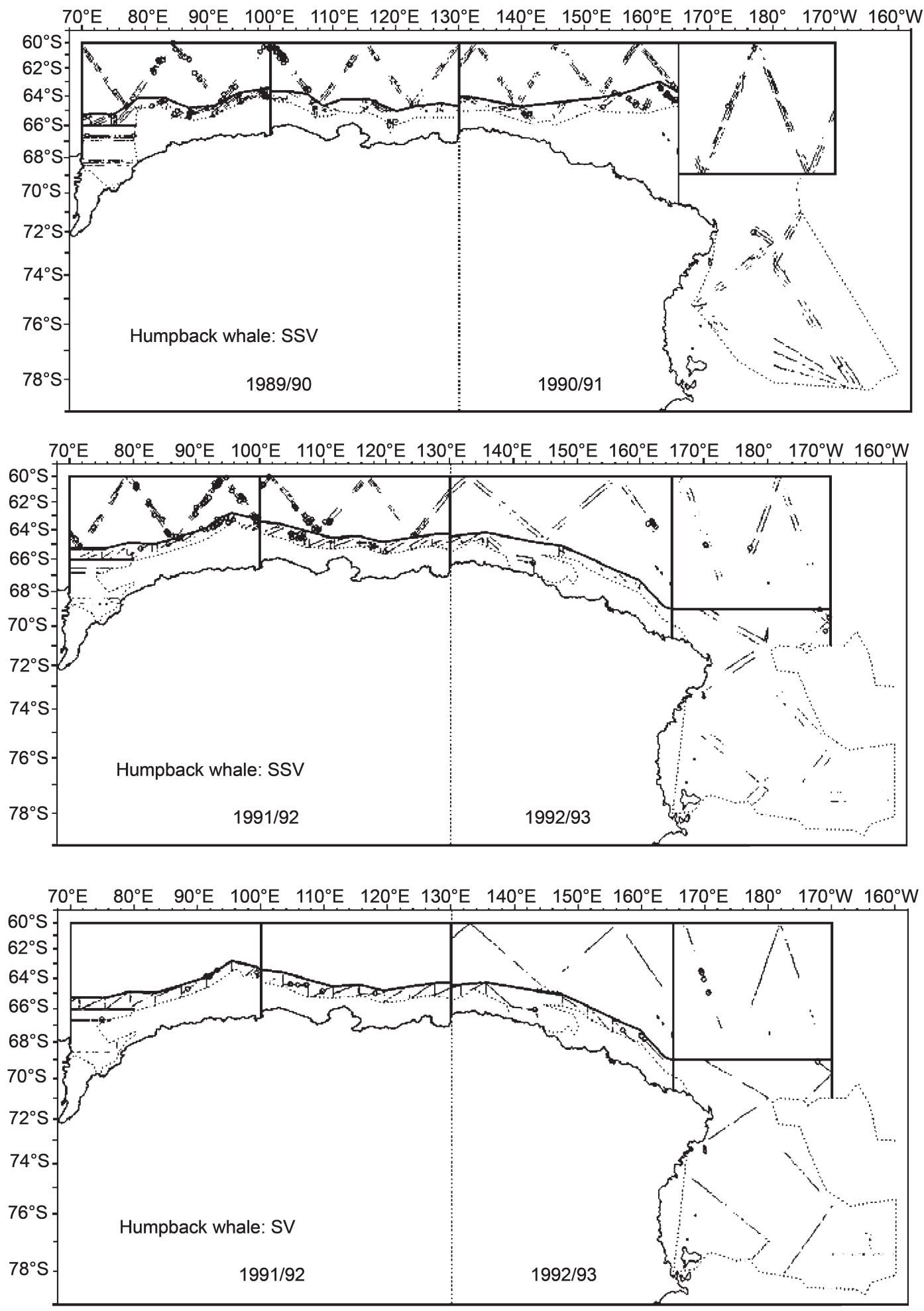

Fig. 1. Primary searching effort (thin lines) and associated primary sightings (circle) of humpback whales in Areas IV and V with the ice edge line (dotted) during the 1989/90 to 2004/05 JARPA surveys. The areas not surveyed in the 1995/96, 1999/00, 2001/02 and 2003/04 seasons are shaded grey. SSV = Sighting and sampling vessels, SV = Dedicated sighting vessel. 


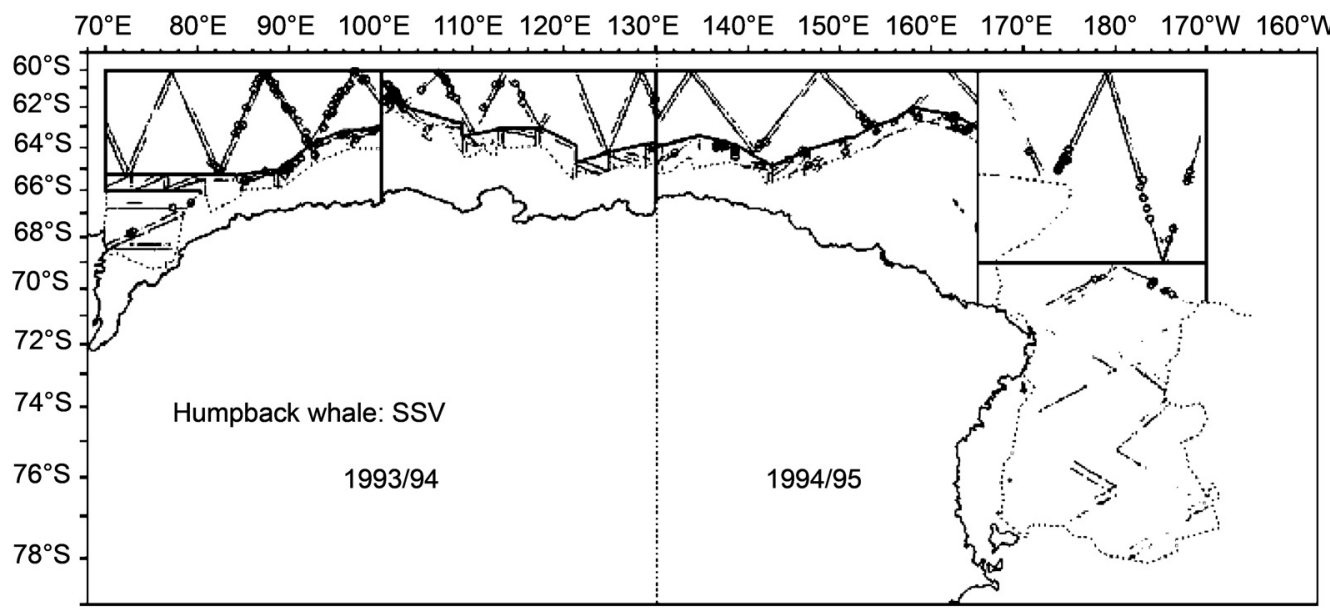

$70^{\circ} \mathrm{E} \quad 80^{\circ} \mathrm{E} \quad 90^{\circ} \mathrm{E} \quad 100^{\circ} \mathrm{E} \quad 110^{\circ} \mathrm{E} \quad 120^{\circ} \mathrm{E} \quad 130^{\circ} \mathrm{E} \quad 140^{\circ} \mathrm{E} \quad 150^{\circ} \mathrm{E} \quad 160^{\circ} \mathrm{E} \quad 170^{\circ} \mathrm{E} \quad 180^{\circ} \quad 170^{\circ} \mathrm{W} \quad 160^{\circ} \mathrm{W}$

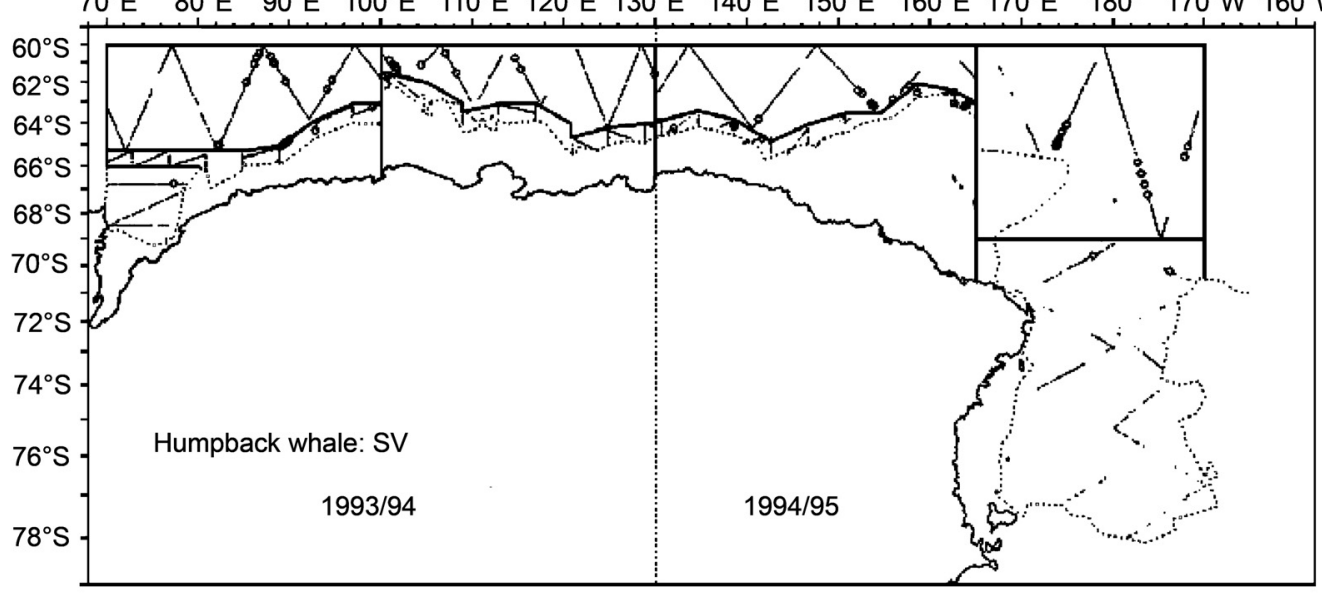

$70^{\circ} \mathrm{E} \quad 80^{\circ} \mathrm{E} \quad 90^{\circ} \mathrm{E} \quad 100^{\circ} \mathrm{E} \quad 110^{\circ} \mathrm{E} \quad 120^{\circ} \mathrm{E} \quad 130^{\circ} \mathrm{E} \quad 140^{\circ} \mathrm{E} \quad 150^{\circ} \mathrm{E} \quad 160^{\circ} \mathrm{E} \quad 170^{\circ} \mathrm{E} \quad 180^{\circ} \quad 170^{\circ} \mathrm{W} \quad 160^{\circ} \mathrm{W}$

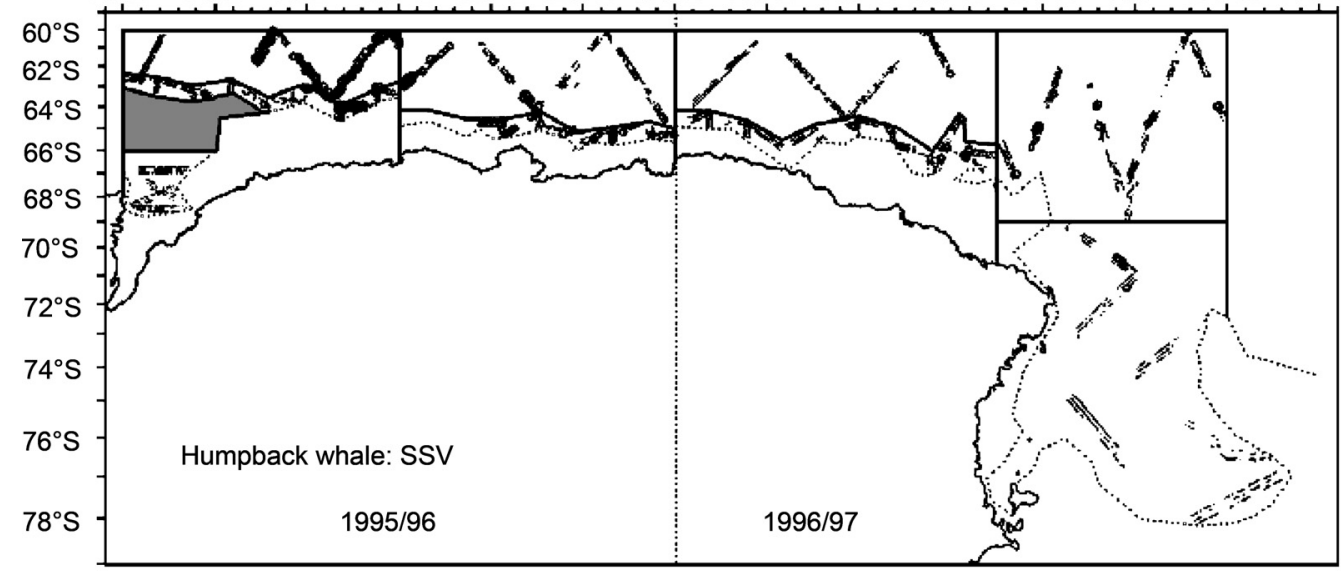

$70^{\circ} \mathrm{E} \quad 80^{\circ} \mathrm{E} \quad 90^{\circ} \mathrm{E} \quad 100^{\circ} \mathrm{E} \quad 110^{\circ} \mathrm{E} \quad 120^{\circ} \mathrm{E} \quad 130^{\circ} \mathrm{E} \quad 140^{\circ} \mathrm{E} \quad 150^{\circ} \mathrm{E} \quad 160^{\circ} \mathrm{E} \quad 170^{\circ} \mathrm{E} \quad 180^{\circ} \quad 170^{\circ} \mathrm{W} \quad 160^{\circ} \mathrm{W}$

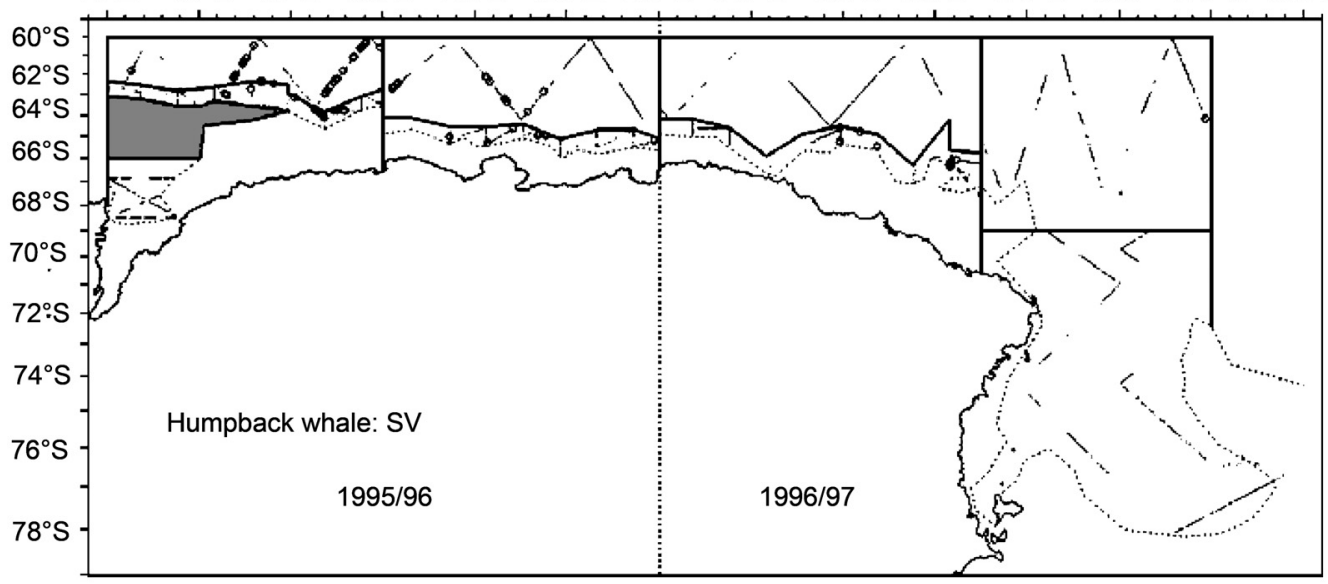



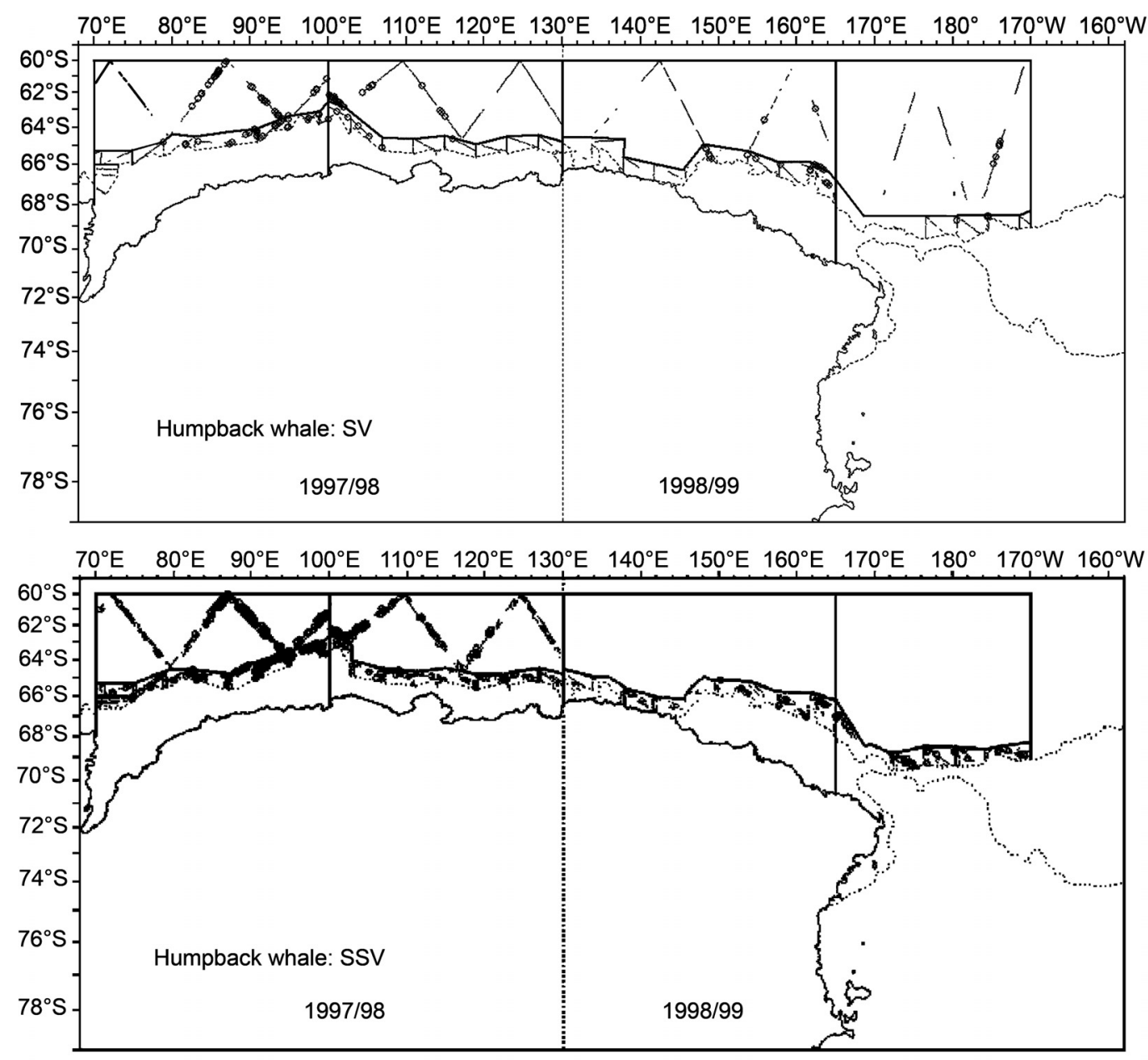

$70^{\circ} \mathrm{E} \quad 80^{\circ} \mathrm{E} \quad 90^{\circ} \mathrm{E} \quad 100^{\circ} \mathrm{E} \quad 110^{\circ} \mathrm{E} \quad 120^{\circ} \mathrm{E} \quad 130^{\circ} \mathrm{E} \quad 140^{\circ} \mathrm{E} \quad 150^{\circ} \mathrm{E} \quad 160^{\circ} \mathrm{E} \quad 170^{\circ} \mathrm{E} \quad 180^{\circ} \quad 170^{\circ} \mathrm{W} \quad 160^{\circ} \mathrm{W}$
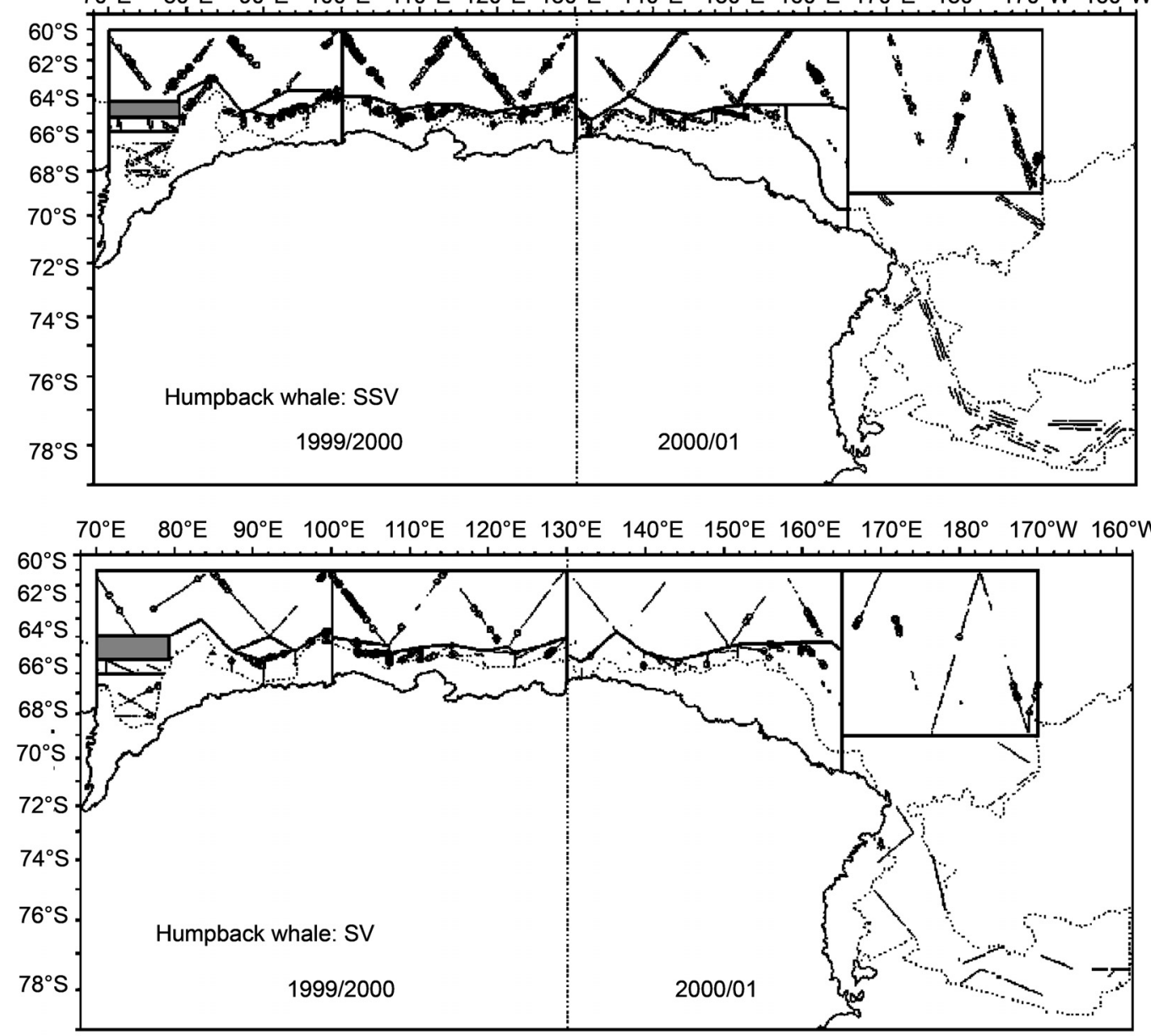

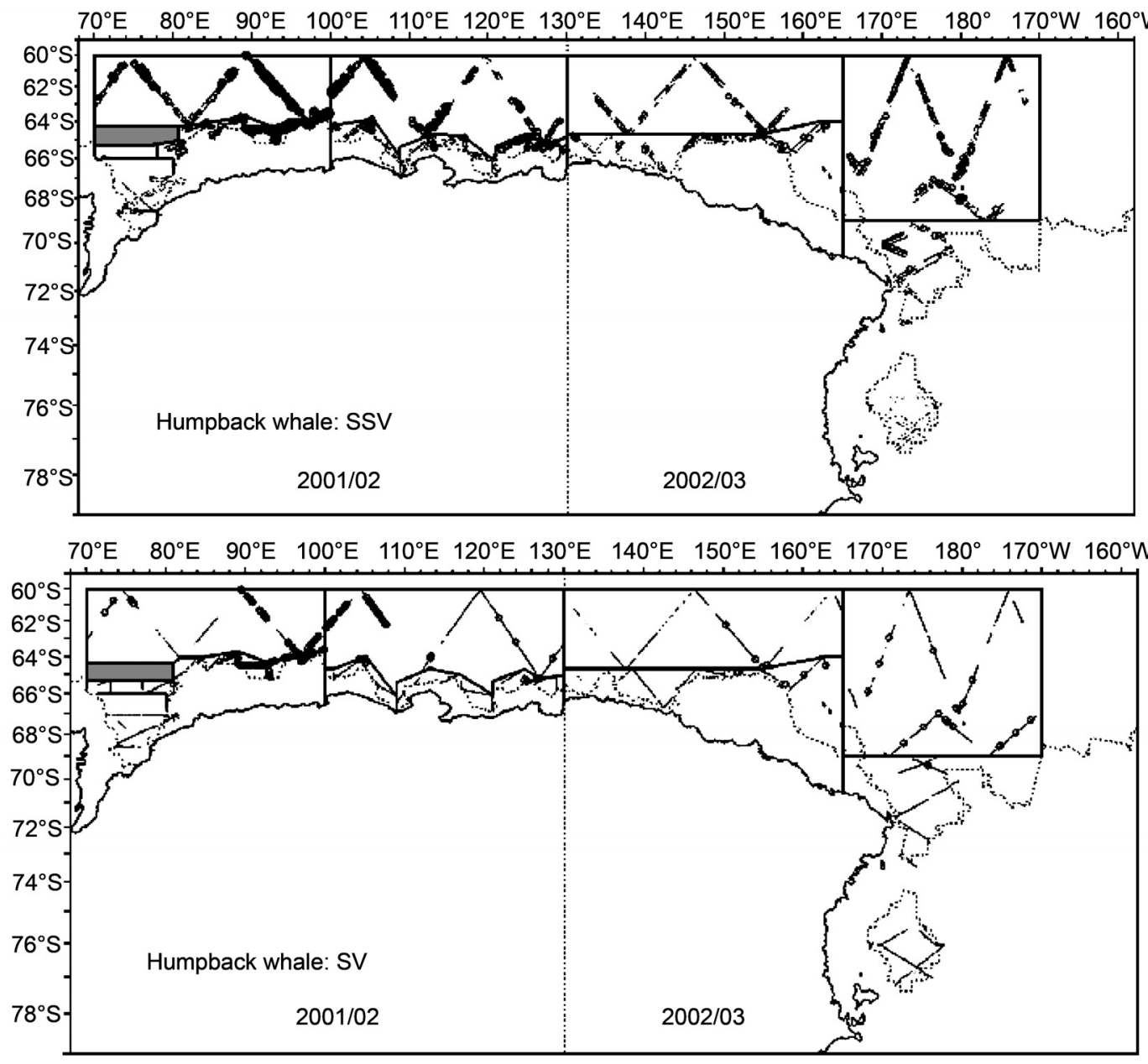

$70^{\circ} \mathrm{E} \quad 80^{\circ} \mathrm{E} \quad 90^{\circ} \mathrm{E} \quad 100^{\circ} \mathrm{E} \quad 110^{\circ} \mathrm{E} \quad 120^{\circ} \mathrm{E} \quad 130^{\circ} \mathrm{E} \quad 140^{\circ} \mathrm{E} \quad 150^{\circ} \mathrm{E} \quad 160^{\circ} \mathrm{E} \quad 170^{\circ} \mathrm{E} \quad 180^{\circ} \quad 170^{\circ} \mathrm{W} \quad 160^{\circ} \mathrm{W}$

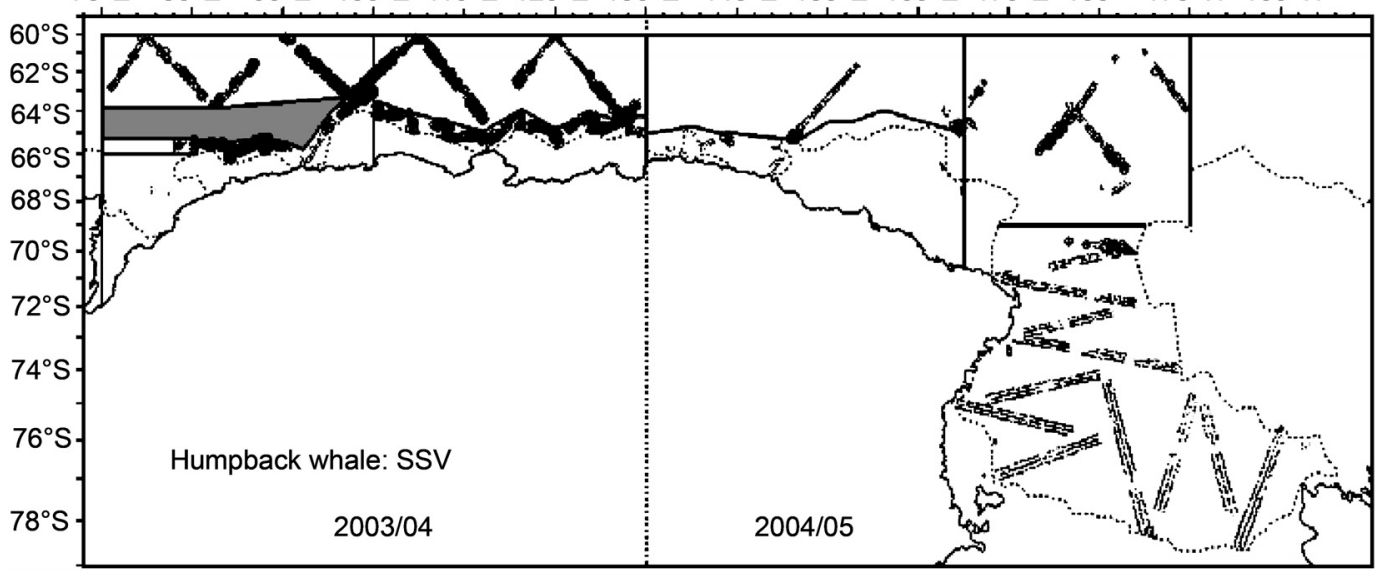

$70^{\circ} \mathrm{E} \quad 80^{\circ} \mathrm{E} \quad 90^{\circ} \mathrm{E} \quad 100^{\circ} \mathrm{E} \quad 110^{\circ} \mathrm{E} \quad 120^{\circ} \mathrm{E} \quad 130^{\circ} \mathrm{E} \quad 140^{\circ} \mathrm{E} \quad 150^{\circ} \mathrm{E} \quad 160^{\circ} \mathrm{E} \quad 170^{\circ} \mathrm{E} \quad 180^{\circ} \quad 170^{\circ} \mathrm{W} \quad 160^{\circ} \mathrm{W}$

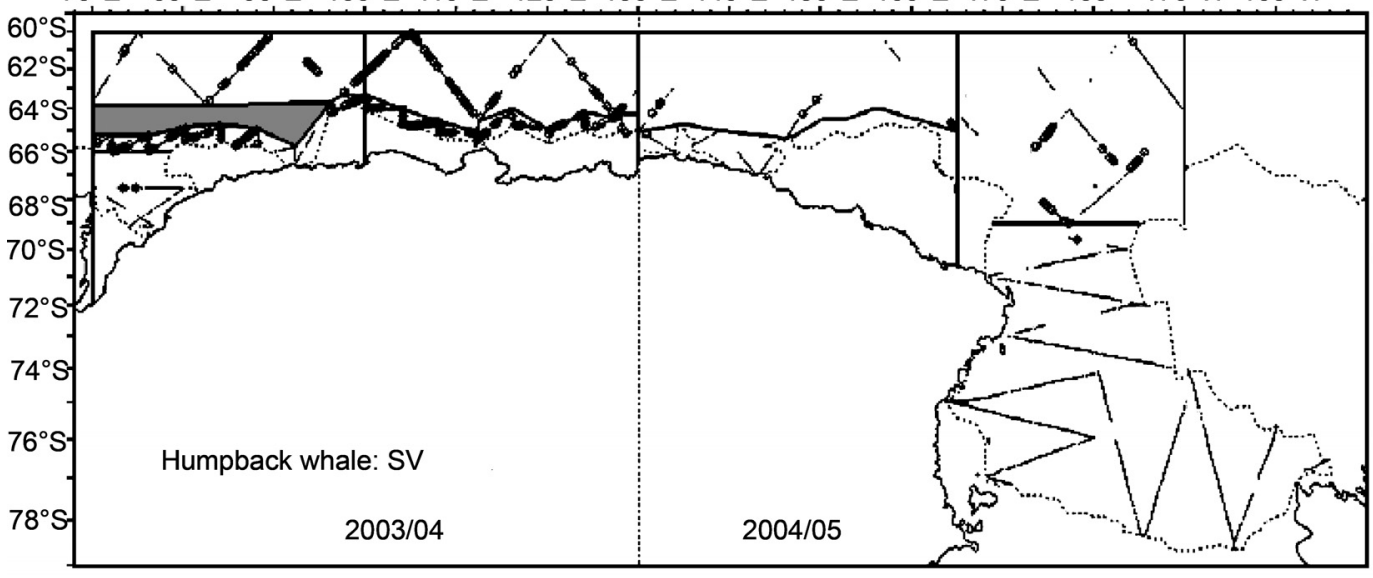




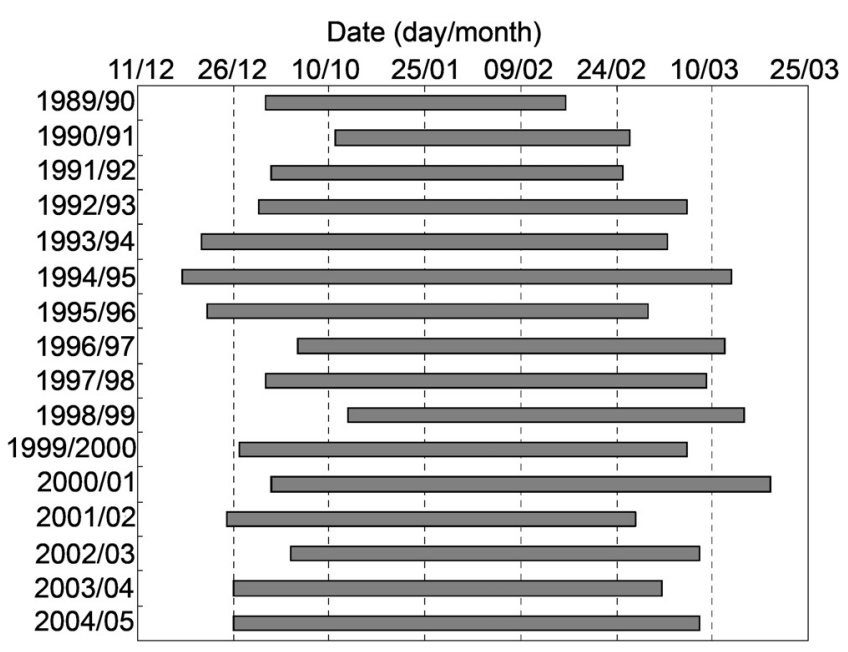

Fig. 2. Start and end dates of JARPA surveys for abundance estimation of humpback whales in Areas IV and V.

surveys (Figs 1 and 4). The saw-tooth type trackline for the southern strata was chosen to allow for a wide area coverage. The starting points of the trackline were selected at random from 1 n.mile intervals on lines of longitude. Trackline way points were systematically set on the ice edge and on the locus of points 45 n.miles from that edge in southern strata, and on this locus and the $60^{\circ} \mathrm{S}$ latitude line in northern strata. Nishiwaki et al. (2006) provides more details.

\section{Sighting survey procedure}

Two or three SSVs travelled in parallel (7 n.miles apart) on each predetermined trackline. The SSVs surveyed at a standard speed of 11.5 knots. The survey was conducted under what were considered optimal research conditions for Antarctic minke whales (i.e. when visibility was over 2 n.miles and the wind speed was $<25$ knots in the southern strata, $<20$ knots in the northern strata).

The SSVs interchanged tracklines each day to avoid possible bias associated with a fixed location in the pair or triplet of tracklines. Sightings of whales were classified into primary and secondary sightings. Primary sightings were those made under normal searching mode; secondary sightings were those made under other modes (e.g. during closing or chasing modes or off effort). In effect, the sighting surveys by the SSVs were conducted under normal closing mode (NSC in IDCR-SOWER notation as described in Nishiwaki et al., 2006) i.e. after a sighting was made the vessels approached a school of whales to confirm species and school size; this mode is denoted as SSV hereafter.

One of the three SSVs behaved as a SV from the 1991/92 to $1994 / 95$ cruises. From $1995 / 96$ three SSVs and an additional SV (KS2) operating in closing mode (i.e. NSC as above but without lethal sampling of whales) were allocated to the survey. From 1998/99, the SV (KS2) introduced the passing mode option (NSP in IDCR-SOWER notation) i.e. the vessel did not approach the whale after the sighting was made and searching from the barrel continued uninterrupted, except that in some special cases, such as sightings of blue whales, closure was effected once the vessel came abeam of the whale. During a 12-hour survey day, the observers alternated between normal closing mode ( 4 hours) and passing modes ( 8 hours). For the SV these modes are denoted as SVC and SVP hereafter. The SSVs followed the $\mathrm{SV}$ at a distance of over 12 n.miles to avoid any influence of sampling activities on the SV's sighting survey.

A researcher on board recorded all the information on the whales sighted. The sighting record included the date and the time of the sighting, the position of the vessel, a classification of survey mode and sighting (primary or secondary), the angle and distance from the vessel of the initial sighting, the species and school size, the estimated body length and other information as for the IDCR-SOWER cruises. More details of these procedures are given in Nishiwaki et al. (2006).

\section{ANALYTICAL PROCEDURE}

The procedure applied here to analyse the sightings data is similar to that used for the IWC/IDCR-SOWER surveys by Branch and Butterworth (2001a; 2001b). To provide 'base case' estimates of abundance:

(1) distances and angles are corrected for possible bias by using the results of the distance and angle estimation experiments;

(2) the sighting rate is obtained for each day;

(3) smearing parameters are obtained by Buckland and Anganuzzi's (1988) method II;

(4) $g(0)$ is assumed to be 1 ; and

(5) sightings data are pooled each season and across strata to the extent necessary for reliable estimation of the effective search half-width ( $w$, using either a hazard rate or half-normal model) and the mean school size $(E(s))$, based on standard line transect analysis methods using the program DISTANCE (Thomas et al., 2005).

The sections below set out further assumptions made to obtain base case estimates, followed by descriptions of sensitivity tests in which one or more of the base case specifications and assumptions are varied.

\section{Data selected for the analysis}

Size of the research area

The surveys covered the region between the ice edge and $60^{\circ} \mathrm{S}$, The open water area for each stratum for each survey

Table 2

Specifications of the research vessels used for the JARPA surveys.

\begin{tabular}{|c|c|c|c|c|c|c|}
\hline & Kyo-maru No.1 & Toshi-maru No.25 & Toshi-maru No. 18 & Yushin-maru & Yushin-maru No.2 & Kyoshin-maru No.2 \\
\hline Call sign & JKNG & 8JCG & JPMQ & JLZS & JPPV & JFHR \\
\hline Register length (m) & 69.15 & 68.37 & 63.20 & 69.61 & 69.60 & 68.18 \\
\hline Gross register tonnage & 812.08 & 739.92 & 758.33 & 720.00 & 747.00 & 372.00 \\
\hline Barrel height (m) & 18.00 & 18.00 & 18.00 & 18.00 & 18.00 & 17.00 \\
\hline IOP height $(\mathrm{m})$ & - & - & - & 13.50 & 13.50 & 10.50 \\
\hline Upper bridge height (m) & 10.00 & 10.00 & 10.00 & 10.00 & 10.00 & 8.00 \\
\hline Maximum continuous output (hp) & 5,000 & 3,600 & 3,500 & 5,280 & 5,280 & 2,100 \\
\hline
\end{tabular}


(a) Area IV
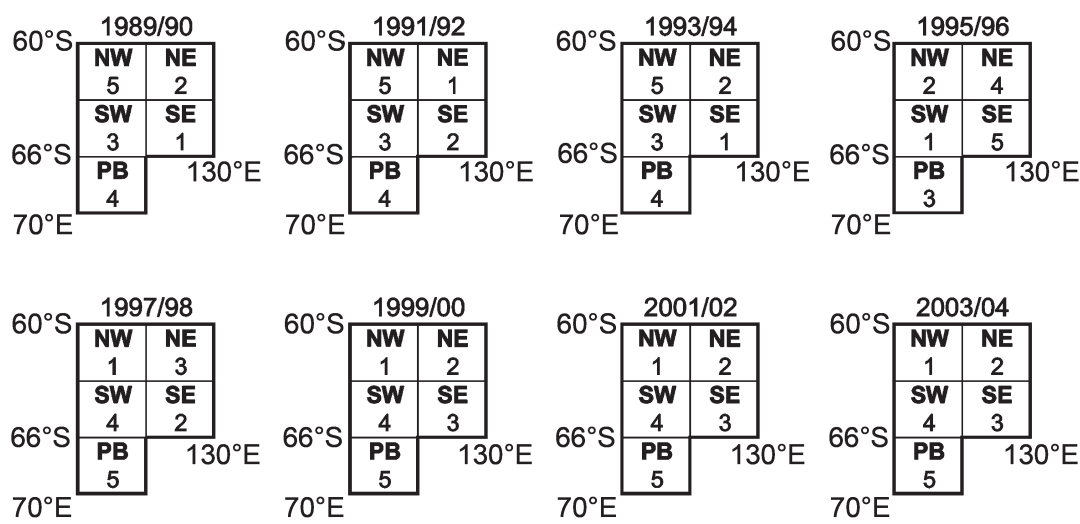

(b) Area V
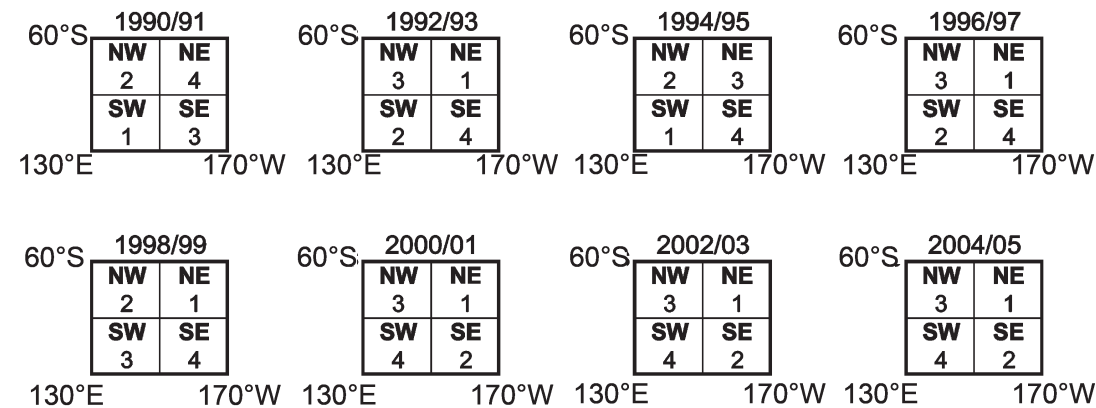

Fig. 3. Survey order by strata. (a) Antarctic Area IV of JARPA survey from the 1989/90 to 2003/04 seasons (b) Antarctic Area V of JARPA survey from the 1990/91 to 2004/05 seasons. Key: NW = North-West, $\mathrm{NE}=$ North-East, SW = South-West, SE = South-East (Ross Sea), PB = Prydz Bay.

was calculated using the Marine Explore Geographical Information System version 4 (Environment Simulation Laboratory Co, Ltd, Japan). The ice edges and hence boundaries between the northern and southern strata differed for SVs and SSVs because their surveys were not completely synchronous, so that the ice edges they encountered differed. This results in slightly different stratum areas for the two. For abundance estimates developed combining data over the SSV and SV modes, the averages of the two area sizes for each stratum are used.

\section{Unsurveyed area}

Some small parts of Area IV were unsurveyed on four of the cruises, with the proportions not surveyed listed in Table 3. These 'gaps' (see Fig. 1) arose because of the retreat of the ice edge after survey of the more northerly of the two strata concerned had been completed, necessitating re-location of the trackline for the more southerly stratum. For base case abundance estimates, these gaps are treated as having the same density as the more northerly stratum. This is because densities tend to be higher closer to the ice edge, and these gap regions are more typical of areas more distant from the ice. Note that such 'gaps' differ from instances where coverage of a survey was poor or incomplete because of shortage of time and/or bad weather. The consequences for abundance estimates of each of these effects are addressed further below under 'Sensitivity Tests'.

\section{Survey modes}

Sightings data collected under SSV, SVC and SVP modes were combined for the estimation of the mean school size and effective search half-width for schools. Although separate estimates are obtained for each of these modes in the case of Antarctic minke whales (Hakamada et al., 2007), data were pooled here. This is because the limited number of sightings made of humpback whales required the inclusion of as many sightings as possible, as in the case of the IDCRSOWER based abundance estimates for species other than the Antarctic minke whale (Branch, 2011; Branch and Butterworth, 2001a).

\section{ABUNDANCE ESTIMATION}

The methodology used for abundance estimation is described in Branch and Butterworth (2001a) and has been accepted by the IWC Scientific Committee in the past. The program DISTANCE (Thomas et al., 2002) was used to implement this. The basic formula is;

$$
P=\frac{A E(s) n}{2 w s L}
$$

where,

$P$ is the estimated abundance in numbers in the stratum,

$A$ is the open ocean area of the stratum,

$E(s)$ is the estimated mean school size,

$n$ is the number of primary sightings of schools,

$w_{s}$ is the effective strip half-width for schools, and

$L$ is the primary search effort.

The CV of $P$ is calculated using the approximate formula:

$$
\mathrm{CV}(P)=\sqrt{\left\{\mathrm{CV}\left(\frac{n}{L}\right)\right\}^{2}+\{\mathrm{CV}(E(s))\}^{2}+\left\{\mathrm{CV}\left(w_{s}\right)\right\}^{2}}
$$




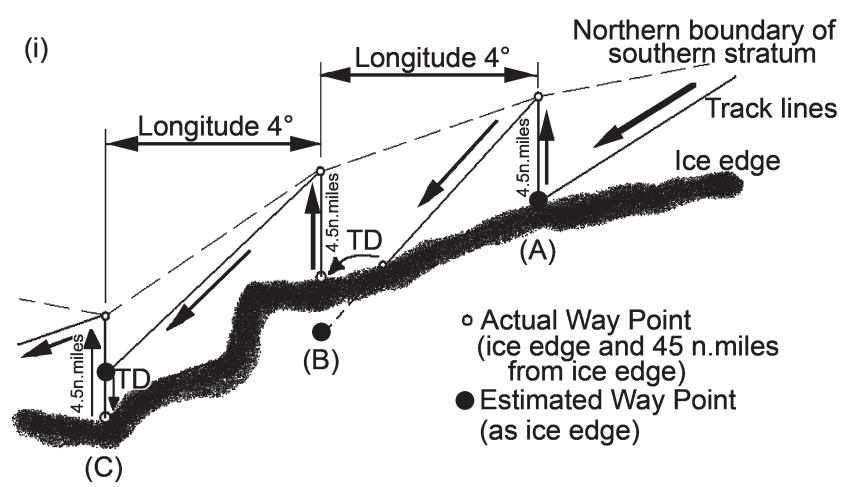

(ii)

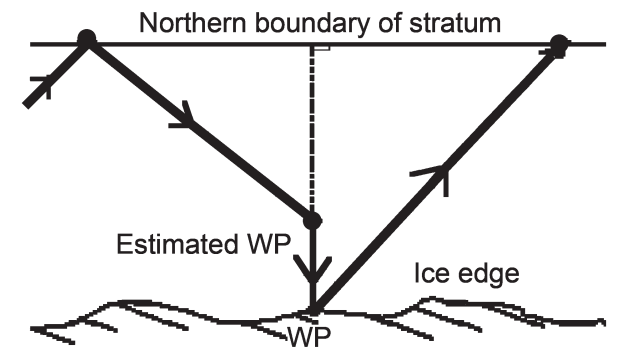

Fig. 4. Trackline design in southern strata. (i) (A): saw tooth shape trackline with intervals of four degrees longitude. Southern way points (WPs) were set on the ice-edge and northern WPs (northern boundary) were set on the locus of points 45 n.miles from the edge. (B): When the ice edge was encountered before reaching a planned southern WP (estimated WP), the research vessels stopped surveying and moved to the next four degree longitudinal interval line along the ice edge (in TD - topman down mode). Then the research vessels reversed direction and resumed the survey (BC in NSC and BP in NSP modes) northward. (C): When the ice edge was not encountered on reaching a planned southern WP, the research vessels stopped surveying and moved south (in TD - topman down - mode) on the longitudinal line through the WP until the vessels encountered the ice edge. Then the research vessels reversed direction and resumed the survey (BC in NSC and BP in NSP modes) northward. (ii) In the case of surveys in the Ross Sea, survey was continued on a bisector line after reaching an estimated southern WP. If the time elapsed from the estimated WP to the true WP on the ice edge was over two hours, a revised trackline was set from the true WP to the next WP on the northern boundary.

Under the assumption of distribution log-normality, 95\% confidence intervals for the abundance estimates are calculated as $(P / C, C P)$ where $C$ is given by:

$$
C=\exp \left(Z_{0.025} \sqrt{\left.\log _{e}\left[1+\{\mathrm{CV}(P)\}^{2}\right]\right)}\right.
$$

and

$Z_{0.025}$ represents 2.5 -percentage point of a standard normal distribution. More details of the analysis methods may be found in Buckland et al. (2001) and Branch and Butterworth (2001a; 2001b).

\section{Correction of the estimated angle and distance}

To be able to detect and if necessary correct for biases in angle and distance observations, experiments using a radar reflecting buoy were conducted by each vessel during each cruise as is the case for the IDCR/SOWER cruises (the experimental methodology is described in Nishiwaki et al., 2006). Linear regression models were used to examine possible differences between observed and true (obtained from radar) distances for each platform for each cruise (Table 4a). In order to correct for such biases, the estimated distance was divided by the estimated slope of a regression through the origin if this slope differed significantly from 1 at the 5\% level. A similar
Table 3

The percentages of the open ocean area not surveyed in Area IV surveys.

\begin{tabular}{cc}
\hline Season & Percentage of area not surveyed \\
\hline $1989 / 90$ & - \\
$1991 / 92$ & - \\
$1993 / 94$ & - \\
$1995 / 96$ & 9.2 \\
$1997 / 98$ & - \\
$1999 / 00$ & 4.5 \\
$2001 / 02$ & 2.7 \\
$2003 / 04$ & 10.0 \\
\hline
\end{tabular}

approach was used for angles. More details of the methodology may be found in Branch and Butterworth (2001b).

\section{Truncation distance}

The conventional truncation distance for perpendicular distances of sightings estimated for Antarctic minke whales is 1.5 n.miles (Branch and Butterworth, 2001b). However, because of their larger body and blow sizes, humpback whales can be seen much further from vessels than Antarctic minke whales. The approximation advocated in Buckland et al. (2001) to truncate such that about $5 \%$ of the data are excluded, has therefore been applied as in Branch and Butterworth (2001a), with results rounded to the nearest 0.3 n.miles. Accordingly the perpendicular distance distributions were truncated at 2.7 n.miles.

\section{Smearing parameters}

Smearing parameters were calculated for each cruise to make allowance for errors in estimates of distances and angles following Branch and Butterworth (2001a). The sightings data are smeared before their truncation to give $n$, and then used in the estimation of the effective search half-width $\left(w_{s}\right)$ and the mean school size $(E(s))$ for input to equation (1). Radial distance and angle data were smeared in the conventional manner by using Method II of Buckland and Anganuzzi (1988) and then grouped into intervals of 0.3 n.miles for estimating $w_{s}$ values. For Antarctic minke whales, smearing parameters are conventionally estimated separately for each stratum from the data. However, due to the lower numbers of sightings of humpback whales, some pooling was necessary here to obtain robust estimates from the Buckland and Anganuzzi method. The smearing parameter values reported in Table $4 \mathrm{~b}$ were thus obtained from pooled sightings (including sightings with both confirmed and unconfirmed school size) separately for each cruise.

\section{Effective search half-width}

The smeared and truncated sighting data for schools were grouped into intervals of 0.3 n.miles to estimate the detection function. A hazard rate model with no adjustment terms and a half-normal model were considered as potential detection functions. The better model was selected by AIC in each case; $g(0)$ was assumed to be 1 (i.e. no schools present on the trackline were missed).

\section{Mean school size}

The method regressing the logarithm of school size against the detection $f(y)$, as described by Buckland et al. (2001) was used to estimate mean school size $(E(s))$. If the regression coefficient was not significant at the $15 \%$ level, the mean of the observed school size was input to equation (1). Note that pooling across survey modes means use of school size estimates for SVP mode which may bias the estimate of $E(s)$ 
Table 4a

Estimated observer bias (expressed as multiplicative correction factors) in distance and angle estimation for JARPA surveys from 1989/90 to 2004/05.

\begin{tabular}{|c|c|c|c|c|c|}
\hline \multirow[b]{3}{*}{ Season } & \multirow[b]{3}{*}{ Vessel } & \multicolumn{4}{|c|}{ Platform } \\
\hline & & \multicolumn{2}{|c|}{ Barrel } & \multicolumn{2}{|c|}{ Upper bridge } \\
\hline & & Distance & Angle & Distance & Angle \\
\hline \multirow[t]{3}{*}{$1989 / 90$} & K01 & n.s. & 0.930 & n.s. & 0.872 \\
\hline & T18 & n.s. & 1.047 & n.s. & n.s. \\
\hline & $\mathrm{T} 25$ & 1.099 & n.s. & 1.075 & n.s. \\
\hline \multirow[t]{3}{*}{ 1990/91 } & K01 & n.s. & 1.051 & 0.953 & 1.064 \\
\hline & $\mathrm{T} 18$ & n.s. & n.s. & n.s. & n.s. \\
\hline & $\mathrm{T} 25$ & 0.882 & n.s. & 0.961 & n.s. \\
\hline \multirow[t]{3}{*}{$1991 / 92$} & K01 & 0.930 & n.s. & n.s. & 0.950 \\
\hline & T18 & n.s. & n.s. & 0.960 & n.s. \\
\hline & $\mathrm{T} 25$ & n.s. & n.s. & 1.070 & n.s. \\
\hline \multirow[t]{3}{*}{$1992 / 93$} & K01 & n.s. & 0.942 & 1.083 & 0.941 \\
\hline & $\mathrm{T} 18$ & n.s. & n.s. & n.s. & n.s. \\
\hline & $\mathrm{T} 25$ & n.s. & 1.056 & n.s. & 1.082 \\
\hline \multirow[t]{3}{*}{$1993 / 94$} & K01 & 0.863 & n.s. & n.s. & n.s. \\
\hline & $\mathrm{T} 18$ & n.s. & n.s. & n.s. & n.s. \\
\hline & $\mathrm{T} 25$ & n.s. & n.s. & n.s. & 1.057 \\
\hline \multirow[t]{3}{*}{$1994 / 95$} & K01 & n.s. & n.s. & n.s. & 0.933 \\
\hline & $\mathrm{T} 18$ & n.s. & n.s. & 0.934 & n.s. \\
\hline & $\mathrm{T} 25$ & 0.940 & n.s. & 0.902 & n.s. \\
\hline \multirow[t]{4}{*}{$1995 / 96$} & K01 & n.s. & n.s. & n.s. & n.s. \\
\hline & $\mathrm{T} 18$ & n.s. & n.s. & 1.110 & 0.956 \\
\hline & $\mathrm{T} 25$ & 0.889 & n.s. & 0.905 & 1.040 \\
\hline & $\mathrm{KS} 2$ & n.s. & 0.905 & n.s. & 0.898 \\
\hline \multirow[t]{4}{*}{$1996 / 97$} & K01 & 0.822 & n.s. & 0.844 & n.s. \\
\hline & $\mathrm{T} 18$ & 0.711 & n.s. & n.s. & n.s. \\
\hline & $\mathrm{T} 25$ & 0.799 & n.s. & 0.773 & 1.036 \\
\hline & $\mathrm{KS} 2$ & 0.789 & 0.951 & 0.662 & 1.050 \\
\hline \multirow[t]{4}{*}{$1997 / 98$} & K01 & 0.842 & n.s. & 0.746 & n.s. \\
\hline & T18 & 0.902 & n.s. & 0.788 & n.s. \\
\hline & $\mathrm{T} 25$ & 0.729 & n.s. & 0.914 & n.s. \\
\hline & KS2 & 0.876 & n.s. & 0.788 & n.s. \\
\hline \multirow[t]{4}{*}{ 1998/99 } & K01 & 0.902 & n.s. & 0.956 & 1.057 \\
\hline & $\mathrm{T} 25$ & n.s. & 1.053 & n.s. & 1.065 \\
\hline & YS1 & 0.923 & n.s. & 0.968 & n.s. \\
\hline & $\mathrm{KS} 2$ & 0.928 & 0.950 & n.s. & n.s. \\
\hline \multirow[t]{4}{*}{$1999 / 2000$} & K01 & n.s. & n.s. & 1.050 & n.s. \\
\hline & $\mathrm{T} 25$ & n.s. & 1.081 & n.s. & n.s. \\
\hline & YS1 & n.s. & n.s. & n.s. & n.s. \\
\hline & $\mathrm{KS} 2$ & n.s. & 0.930 & n.s. & n.s. \\
\hline $2000 / 2001$ & K01 & n.s. & 1.051 & n.s. & n.s. \\
\hline & $\mathrm{T} 25$ & n.s. & n.s. & 1.062 & n.s. \\
\hline & YS1 & n.s. & n.s. & n.s. & n.s. \\
\hline & $\mathrm{KS} 2$ & n.s. & n.s. & n.s. & 0.861 \\
\hline $2001 / 2002$ & K01 & 0.957 & 0.921 & 0.957 & n.s. \\
\hline & $\mathrm{T} 25$ & 0.951 & n.s. & 0.960 & n.s. \\
\hline & YS1 & n.s. & n.s. & n.s. & n.s. \\
\hline & $\mathrm{KS} 2$ & n.s. & n.s. & n.s. & n.s. \\
\hline $2002 / 2003$ & K01 & 1.073 & n.s. & n.s. & n.s. \\
\hline & YS1 & 1.051 & 1.037 & 1.058 & 0.938 \\
\hline & YS2 & 1.050 & n.s. & n.s. & n.s. \\
\hline & $\mathrm{KS} 2$ & n.s. & n.s. & n.s. & 1.088 \\
\hline $2003 / 2004$ & K01 & 0.957 & 0.921 & 0.957 & n.s. \\
\hline & YS1 & 0.951 & n.s. & 0.960 & n.s. \\
\hline & YS2 & n.s. & n.s. & n.s. & n.s. \\
\hline & $\mathrm{KS} 2$ & n.s. & n.s. & n.s. & n.s. \\
\hline $2004 / 2005$ & K01 & 1.113 & 1.096 & 1.044 & n.s. \\
\hline & YS1 & 1.029 & 0.939 & 1.024 & 0.919 \\
\hline & YS2 & 1.102 & 1.061 & n.s. & n.s. \\
\hline & $\mathrm{KS} 2$ & 1.084 & 0.966 & 1.064 & n.s. \\
\hline
\end{tabular}

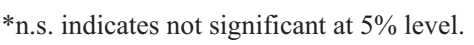

Table $4 \mathrm{~b}$

Smearing parameters for each stratum used in abundance estimation. Units for angles are degrees, while for distances the values given are proportions.

\begin{tabular}{|c|c|c|c|c|c|}
\hline \multirow[b]{2}{*}{ Season } & \multicolumn{2}{|c|}{ Area IV } & \multirow[b]{2}{*}{ Season } & \multicolumn{2}{|c|}{ Area V } \\
\hline & Angle & Distance & & Angle & Distance \\
\hline $1989 / 90$ & 4.978 & 0.308 & $1990 / 91$ & 3.963 & 0.257 \\
\hline $1991 / 92$ & 6.589 & 0.266 & $1992 / 93$ & 4.616 & 0.396 \\
\hline $1993 / 94$ & 5.821 & 0.356 & $1994 / 95$ & 6.411 & 0.206 \\
\hline $1995 / 96$ & 5.742 & 0.273 & $1996 / 97$ & 7.732 & 0.214 \\
\hline $1997 / 98$ & 5.612 & 0.231 & 1998/99 & 8.710 & 0.281 \\
\hline $1999 / 2000$ & 6.769 & 0.233 & $2000 / 01$ & 6.559 & 0.307 \\
\hline $2001 / 02$ & 5.289 & 0.233 & $2002 / 03$ & 4.106 & 0.174 \\
\hline $2003 / 04$ & 7.180 & 0.188 & $2004 / 05$ & 6.486 & 0.250 \\
\hline
\end{tabular}

downwards. Only sightings for which school size was confirmed were used to obtain these estimates.

\section{Population rate of increase}

To estimate rate of increase in an Area, an exponential trend was assumed with the following error structure:

$$
P_{y}=\beta \exp (\alpha y)+v_{y}, \hat{P}_{y}=P_{y}+u_{y},
$$

where

$P_{y}$ and $\hat{P}_{y}$ are the true and survey estimated abundances in an Area in season $y$,

$\alpha$ is the instantaneous increase rate,

$\beta$ is abundance for season $y=0$,

$u_{y}$ reflects survey sampling error, and

$v_{y}$ is the error associated with additional variance, which arises from an inter-annual variation in the proportion of whales in the surveyed area at the time of the survey.

In order to take the additional variance of abundance estimates $\left(\mathrm{CV}_{\text {add }}\right)$ as well as the survey sampling $\mathrm{CV}$ into account, the negative log-likelihood function minimised to estimate is:

$$
\begin{aligned}
l\left(\alpha, \beta, C V_{a d d}\right) & =\frac{1}{2} \sum_{y} \log \left[C V\left(\hat{P}_{y}\right)^{2}+C V_{a d d}^{2}\right] \\
& +\sum_{y} \frac{\left(\log \left(\hat{P}_{y}\right)-\log (\beta)-\alpha y\right)^{2}}{2\left[\left\{C V\left(\hat{P}_{y}\right)\right\}^{2}+C V_{a d d}^{2}\right]}
\end{aligned}
$$

Estimates of standard errors for and $\mathrm{CV}_{\text {add }}$ were obtained from the associated Hessian (Information matrix), with CI estimates assuming a $t$-distribution with 6 degrees of freedom.

\section{Sensitivity tests}

Alternative estimates of effective search half-width

The base case selects between the hazard rate and halfnormal models for the detection function for cruisestratum/set-of-strata combinations. For sensitivity tests, either all forms are set to half-normal or all to hazard rate.

\section{Inclusion of tracklines that followed the contours of the ice} edge

In practice, some of the tracklines obtained where the sawtooth type trackline design approach was used, were nearly parallel to the ice edge (e.g. SW and SE strata in Area IV). 
This could lead to overestimation of abundance because of possible higher density close to the ice edge. As sensitivity tests to examine the effect of tracklines that followed the contours of the ice edge, two datasets were developed: one that excluded portions of tracklines that followed the contours of the ice edge (Option B), and the other one that excluded all tracklines not parallel to lines of longitude (Option C). Given the small number of sightings in the SW and SE strata in Area IV on earlier cruises, only seasons from 1997/98 onwards were considered.

\section{Unsurveyed areas and incomplete coverage}

Two approaches have been taken to attempt to bound the uncertainty associated with the treatment of 'gaps' in coverage as defined above for the base case estimates:

(1) the abundance contributions from these gaps are set to zero (i.e. whales in such gaps at the time of surveying the more southerly strata are considered as ones already effectively counted in the earlier surveying of the more northerly strata, as these whales would subsequently likely have moved further south); and

(2) the density in a gap is assumed to be the same as the higher density in the stratum immediately to the south, rather than that immediately to the north as in the base case.

The implications of incomplete to poor coverage of certain strata as a result of time shortage or weather factors also need consideration. Selection of potentially more serious cases to examine was guided by inspection of the cruise track plots in Fig. 1, and instances where a review by Wade (2008) suggested coverage to be 'low' in the sense of less than about $50 \%$. However, because for humpback whales, the data for SSV and SV surveys are combined, only cases where coverage was incomplete or poor for both these two survey modes were considered further. Further, following consideration of the extent of the poor coverage together with the contribution from the stratum concerned to the abundance estimate for the complete Area for that cruise, sensitivity to instances of poor or incomplete coverage in Area V for the SE stratum in 2002/03 and the SW stratum in 2004/05 was deemed likely to be slight and further calculations for those cases were not pursued.

For the remaining cases, the approach followed to examine sensitivity was as follows. For the base case estimates of abundance, the extrapolated density for the (nearly) unsurveyed portion of a stratum is taken to be the same as that in the surveyed portion of the stratum. For an alternative to this, the average of the ratio of the densities in these two portions of the stratum on other cruises was evaluated (in the case of this humpback analysis this amounts to considering the ratio of sighting rates, as values of other inputs to the calculation of density are common), and this was used instead to extrapolate the density in the surveyed to that for the (nearly) unsurveyed portion for the season in question. The development of such averages did not include data from every other cruise, as consideration was also given to similarities of ice-edge configurations between the cruises. The strata for which such alternative computations were conducted, together with the other cruises used to develop the average ratio required shown in parenthesis, were as follows:

Area IV: $1995 / 96$ SE over $100^{\circ}-108^{\circ} \mathrm{E}(1989 / 90 ; 1991 / 92$; $1997 / 98 ; 1999 / 00 ; 2003 / 04)$

Area V: $1990 / 91$ SE over $69^{\circ}-71^{\circ} \mathrm{S}$ (1992/93; 1994/95; 1996/97; 2004/05)
Area V: $1992 / 93 \mathrm{NE}$ over $68^{\circ}-69^{\circ} \mathrm{S}(2002 / 03 ; 2004 / 05)$

Area V: $2000 / 01$ SE over $69^{\circ}-71^{\circ} \mathrm{S} \quad(1992 / 93 ; 1994 / 95$; 1996/97; 2004/05)

Area V: $2004 / 05$ NW over $130^{\circ}-148^{\circ} \mathrm{E}$ (1998/99; 2000/01; 2002/03)

The effect of survey modes and survey timing

To investigate the extent of effects of the survey modes (i.e. SSV, SVC and SVP) and timing of the survey conducted in each stratum (which differed in some years because of differences in the order in which the strata were surveyed) on estimates of population increase rates, GLM analyses were undertaken. In the Prydz Bay stratum in Area IV and the SE stratum in Area V, no sightings of humpback whales were made for some of the cruises. Hence a Poisson error structure was assumed for the GLMs. A hierarchy of such models was evaluated for each Area. As discussed in Hakamada et al. (2007), because stratum areas vary from season to season as a result of different ice edge locations, it is not immediately obvious whether such approaches should be based on the density or on the abundance in a stratum, and arguments can be offered to support either approach. However density is perhaps the more obvious choice and furthermore Hakamada et al. (2007) found little difference in results for the two approaches for minke whales. Accordingly the analyses here are based only on density.

$$
\begin{aligned}
& \text { Model (i): } \log E\left[n_{o b s}(y, a)\right]=\log \left(\frac{2 w_{y, a} L_{y, a}}{E_{y, a}(s)}\right) \\
& +\log \left(D_{\text {true }}(0, a)\right)+\alpha y \\
& \text { Model (ii): } \log E\left[n_{o b s}(y, a)\right]=\log \left(\frac{2 w_{y, a} L_{y, a}}{E_{y, a}(s)}\right) \\
& +\log \left(D_{\text {true }}(0, a)\right)+\alpha y+M \\
& \text { Model (iii): } \log E\left[n_{o b s}(y, a)\right]=\log \left(\frac{2 w_{y, a} L_{y, a}}{E_{y, a}(s)}\right) \\
& +\log \left(D_{\text {true }}(0, a)\right)+\alpha y+M+T \\
& \text { Model (iv): } \log E\left[n_{o b s}(y, a)\right]=\log \left(\frac{2 w_{y, a} L_{y, a}}{E_{y, a}(s)}\right) \\
& +\log \left(D_{\text {true }}(0, a)\right)+\alpha y+M+a^{*} T
\end{aligned}
$$

Where:

$y$ is the season,

$a$ is the stratum,

$E\left[n_{\text {obs }}(y, a)\right]$ is the expected number of sightings in stratum $a$ in season $y$,

$w_{y, a}$ is the effective search half-width for season $y$ and stratum $a$,

$L_{y, a}$ is the primary searching distance for season $y$ and stratum $a$,

$E(s)_{y, a}$ is the estimated mean school size for season $y$ and stratum $a$,

$D_{\text {true }}(y, a)$ is the unbiased (i.e. free from the survey mode effect) density for season $y$ and stratum $a$, 
$\alpha$ is the population's exponential rate of increase,

$M$ is the mode factor for SSV and SVC surveys standardised to SVP,

$T$ is a categorical variable related to survey timing that is defined below, and

$a^{*} T$ is an interaction between the stratum $a$ and timing $T$ factors.

The first term on the right-hand-side as known as the offset. It uses values of $w$ and $E(s)$ pooled over modes, so that all inputs required are listed in Tables $5 \mathrm{a}$ and $5 \mathrm{~b}$. The approach used here makes the assumption that the variances of $w_{s}$ and $E(s)$ are relatively small compared to the variance associated with the observed number of sightings. Additional variance has not been considered in these analyses.

The middle day of the survey period in each stratum was calculated and categorised into groups as a basis to specify $T$ for models (iii) and (iv) above. The groups in bold letters below are included in the intercept of the alternative models considered (i.e. the effect of those groups is set to zero in the calculations). Because the estimate of $\alpha$ seemed to be sensitive to the definition of $T$ for Area IV in particular, five groupings were considered:

(1) $\mathrm{T}=1$ : Dec 15-31; $\mathrm{T}=2$ : Jan 1-15; $\mathrm{T}=\mathbf{3}$ : Jan 16-31; $\mathrm{T}$ $=4:$ Feb 1-15; $\mathrm{T}=5:$ Feb 16-29; and $\mathrm{T}=6$ : Mar 1-15 (Grouping T1)

Table 5a

Abundance estimates for humpback whales in Area IV (south of $60^{\circ} \mathrm{S}$ ) from the $1989 / 90$ to $2003 / 04$ JARPA cruises. $A=$ size of research area; $n=$ number of schools sighted on primary effort (truncated at a perpendicular distance of $2.7 \mathrm{n}$.miles after smearing); $L=$ primary searching distance; $w_{s}=$ the effective search half width (hazard rate model estimate, or half normal if shown in italics); $E(s)=$ mean school size; $D=$ estimated density (individuals $/ 100$ n.miles ${ }^{2}$ ); $P=$ estimated abundance.

\begin{tabular}{|c|c|c|c|c|c|c|c|c|c|c|c|c|c|}
\hline Season & Stratum & $A\left(\right.$ n.mile $\left.{ }^{2}\right)$ & $n$ & $L$ (n.mile) & $n / L * 10^{2}$ & $\mathrm{CV}$ & $w_{s}($ n.mile $)$ & $\mathrm{CV}$ & $E(s)$ & $\mathrm{CV}$ & $D$ (ind.) & $P$ (ind.) & $\mathrm{CV}$ \\
\hline \multirow[t]{6}{*}{$1989 / 90$} & NW & 222,563 & 21.2 & $1,987.6$ & 1.067 & 0.297 & 0.996 & 0.226 & 2.000 & 0.093 & 1.071 & 2,383 & 0.331 \\
\hline & $\mathrm{NE}$ & 219,245 & 20.0 & $1,964.4$ & 1.018 & 0.448 & 0.727 & 0.426 & 1.750 & 0.082 & 1.225 & 2,687 & 0.522 \\
\hline & SW & 35,878 & 10.4 & $2,518.3$ & 0.411 & 0.391 & 0.937 & 0.201 & 1.804 & 0.056 & 0.396 & 142 & 0.412 \\
\hline & SE & 41,143 & 1.0 & $1,362.2$ & 0.073 & 0.732 & 0.937 & 0.201 & 1.804 & 0.056 & 0.071 & 29 & 0.761 \\
\hline & PB & 36,488 & 2.0 & 831.9 & 0.240 & 0.482 & 0.937 & 0.201 & 1.804 & 0.056 & 0.231 & 84 & 0.526 \\
\hline & Total & 555,317 & 54.6 & $8,664.4$ & 0.630 & 0.215 & - & - & - & - & 0.959 & 5,325 & 0.302 \\
\hline \multirow[t]{6}{*}{$1991 / 92$} & NW & 219,713 & 41.7 & $2,482.7$ & 1.680 & 0.231 & 1.052 & 0.202 & 1.929 & 0.062 & 1.540 & 3,383 & 0.265 \\
\hline & $\mathrm{NE}$ & 216,299 & 16.0 & $2,173.9$ & 0.736 & 0.300 & 1.005 & 0.143 & 1.803 & 0.049 & 0.661 & 1,429 & 0.317 \\
\hline & SW & 37,191 & 19.7 & $2,237.5$ & 0.880 & 0.350 & 1.379 & 0.172 & 1.680 & 0.082 & 0.536 & 199 & 0.368 \\
\hline & SE & 39,732 & 17.0 & $2,281.7$ & 0.745 & 0.378 & 0.746 & 0.327 & 1.870 & 0.051 & 0.905 & 360 & 0.424 \\
\hline & PB & 36,569 & 1.0 & 607.5 & 0.165 & 0.730 & 1.379 & 0.172 & 1.680 & 0.082 & 0.100 & 37 & 0.755 \\
\hline & Total & 549,504 & 95.4 & $9,783.3$ & 0.975 & 0.150 & - & - & - & - & 0.984 & 5,408 & 0.188 \\
\hline \multirow[t]{6}{*}{$1993 / 94$} & NW & 233,289 & 43.7 & $4,160.7$ & 1.050 & 0.191 & 1.220 & 0.122 & 1.614 & 0.068 & 0.694 & 1,619 & 0.208 \\
\hline & $\mathrm{NE}$ & 163,982 & 30.5 & $3,175.1$ & 0.960 & 0.290 & 1.874 & 0.171 & 1.774 & 0.079 & 0.454 & 744 & 0.310 \\
\hline & SW & 39,755 & 24.8 & $2,377.7$ & 1.043 & 0.338 & 1.381 & 0.157 & 1.571 & 0.070 & 0.597 & 237 & 0.354 \\
\hline & SE & 41,353 & 7.0 & $2,258.9$ & 0.310 & 0.315 & 1.381 & 0.157 & 1.571 & 0.070 & 0.179 & 74 & 0.334 \\
\hline & PB & 34,506 & 4.0 & $1,077.0$ & 0.371 & 0.688 & 1.381 & 0.157 & 1.571 & 0.070 & 0.211 & 73 & 0.701 \\
\hline & Total & 512,885 & 110.0 & $13,049.4$ & 0.843 & 0.138 & - & - & - & - & 0.536 & 2,747 & 0.153 \\
\hline \multirow[t]{6}{*}{$1995 / 96$} & NW & 149,107 & 122.2 & $3,530.5$ & 3.461 & 0.171 & 1.126 & 0.070 & 1.543 & 0.037 & 2.347 & 3,611 & 0.176 \\
\hline & $\mathrm{NE}$ & 230,473 & 45.8 & $2,979.7$ & 1.537 & 0.280 & 1.076 & 0.119 & 1.826 & 0.079 & 1.304 & 3,007 & 0.289 \\
\hline & $\mathrm{SW}^{*}$ & 89,825 & 54.5 & $2,851.2$ & 1.911 & 0.318 & 1.468 & 0.118 & 1.909 & 0.050 & 1.293 & 1,100 & 0.336 \\
\hline & SE & 33,980 & 27.6 & $2,039.9$ & 1.353 & 0.246 & 1.248 & 0.154 & 1.893 & 0.087 & 1.029 & 348 & 0.267 \\
\hline & PB & 25,970 & 0.0 & $1,321.8$ & - & - & - & - & - & - & - & 0 & - \\
\hline & Total & 529,354 & 250.1 & $12,723.1$ & 1.966 & 0.123 & - & - & - & - & 1.524 & 8,066 & 0.142 \\
\hline \multirow[t]{6}{*}{$1997 / 98$} & NW & 217,645 & 191.6 & $3,367.2$ & 5.690 & 0.200 & 1.829 & 0.071 & 1.870 & 0.035 & 2.924 & 6,365 & 0.204 \\
\hline & $\mathrm{NE}$ & 219,602 & 107.2 & $3,622.7$ & 2.959 & 0.367 & 1.681 & 0.085 & 1.658 & 0.040 & 1.465 & 3,217 & 0.369 \\
\hline & SW & 31,615 & 171.3 & $3,432.5$ & 4.991 & 0.157 & 1.533 & 0.064 & 1.767 & 0.030 & 2.944 & 931 & 0.161 \\
\hline & SE & 34,374 & 25.2 & $3,195.9$ & 0.789 & 0.218 & 1.549 & 0.168 & 1.555 & 0.090 & 0.395 & 136 & 0.239 \\
\hline & PB & 4,407 & 2.0 & 490.0 & 0.408 & 0.758 & 1.533 & 0.064 & 1.767 & 0.030 & 0.204 & 9 & 0.761 \\
\hline & Total & 507,643 & 497.3 & $14,108.3$ & 3.525 & 0.123 & - & - & - & - & 2.099 & 10,657 & 0.166 \\
\hline \multirow[t]{6}{*}{$1999 / 2000$} & $\mathrm{NW}^{*}$ & 229,368 & 54.7 & $2,825.3$ & 1.936 & 0.193 & 1.347 & 0.113 & 1.532 & 0.066 & 1.098 & 2,519 & 0.204 \\
\hline & $\mathrm{NE}$ & 226,272 & 160.7 & $3,550.8$ & 4.525 & 0.208 & 0.828 & 0.170 & 1.538 & 0.032 & 4.203 & 9,510 & 0.228 \\
\hline & SW & 44,862 & 106.3 & $2,336.7$ & 4.549 & 0.245 & 0.579 & 0.222 & 1.710 & 0.039 & 6.839 & 3,068 & 0.274 \\
\hline & SE & 34,175 & 165.1 & $2,704.3$ & 6.105 & 0.191 & 1.447 & 0.068 & 2.183 & 0.054 & 4.613 & 1,576 & 0.195 \\
\hline & PB & 21,288 & 3.0 & $1,244.7$ & 0.241 & 0.610 & 0.579 & 0.222 & 1.710 & 0.039 & 0.369 & 78 & 0.651 \\
\hline & Total & 555,964 & 489.8 & $12,661.8$ & 3.868 & 0.110 & - & - & - & - & 3.013 & 16,751 & 0.143 \\
\hline \multirow[t]{6}{*}{$2001 / 02$} & $\mathrm{NW}^{*}$ & 222,449 & 252.2 & $3,043.6$ & 8.286 & 0.191 & 1.259 & 0.071 & 1.941 & 0.035 & 6.371 & 14,171 & 0.196 \\
\hline & $\mathrm{NE}$ & 244,921 & 238.2 & $3,271.6$ & 7.281 & 0.206 & 1.286 & 0.061 & 1.754 & 0.032 & 4.937 & 12,093 & 0.209 \\
\hline & SW & 32,199 & 386.8 & $2,321.8$ & 16.658 & 0.176 & 1.201 & 0.053 & 1.870 & 0.027 & 13.164 & 4,239 & 0.178 \\
\hline & SE & 35,955 & 63.5 & $2,885.2$ & 2.201 & 0.257 & 1.090 & 0.097 & 1.672 & 0.057 & 1.755 & 631 & 0.266 \\
\hline & PB & 28,472 & 0.0 & $1,033.7$ & - & - & - & - & - & - & - & 0 & - \\
\hline & Total & 563,995 & 940.7 & $12,555.9$ & 7.492 & 0.104 & - & - & - & - & 5.520 & 31,134 & 0.123 \\
\hline \multirow[t]{6}{*}{ 2003/04 } & $\mathrm{NW}^{*}$ & 243,849 & 241.2 & $3,236.6$ & 7.452 & 0.249 & 1.334 & 0.051 & 1.680 & 0.026 & 4.728 & 11,529 & 0.248 \\
\hline & NE & 218,072 & 278.9 & $3,738.5$ & 7.460 & 0.137 & 1.495 & 0.050 & 1.666 & 0.025 & 4.152 & 9,053 & 0.140 \\
\hline & SW & 38,976 & 389.3 & $2,275.2$ & 17.111 & 0.112 & 1.417 & 0.063 & 1.886 & 0.021 & 11.315 & 4,410 & 0.117 \\
\hline & $\mathrm{SE}$ & 38,952 & 448.2 & $3,633.2$ & 12.336 & 0.139 & 1.489 & 0.039 & 1.643 & 0.019 & 6.911 & 2,692 & 0.134 \\
\hline & PB & 37,537 & 2.0 & 508.5 & 0.393 & 1.294 & 1.417 & 0.063 & 1.886 & 0.021 & 0.261 & 98 & 1.296 \\
\hline & Total & 577,386 & 1359.6 & $13,392.0$ & 10.152 & 0.077 & - & - & - & - & 4.812 & 27,783 & 0.115 \\
\hline
\end{tabular}

*Including area not surveyed as indicated in Table 3. 
Table $5 b$

Abundance estimates for humpback whales in Area V (south of $60^{\circ} \mathrm{S}$ ) from the $1990 / 91$ to $2004 / 05$ JARPA cruises. The notation is as for Table 5a.

\begin{tabular}{|c|c|c|c|c|c|c|c|c|c|c|c|c|c|}
\hline Season & Stratum & $A\left(\mathrm{n} . \mathrm{mile}^{2}\right)$ & $n$ & $L$ (n.mile) & $n / L^{*} 10^{2}$ & $\mathrm{CV}$ & $w_{s}$ (n.mile) & $\mathrm{CV}$ & $E(s)$ & $\mathrm{CV}$ & $\boldsymbol{D}$ (ind.) & $\boldsymbol{P}$ (ind.) & $\mathrm{CV}$ \\
\hline \multirow[t]{4}{*}{$1990 / 91$} & NW & 239,688 & 1.0 & $2,726.8$ & 0.037 & 1.096 & 1.189 & 0.163 & 1.303 & 0.087 & 0.020 & 48 & 1.111 \\
\hline & NE & 348,822 & 0.0 & $2,498.9$ & - & - & - & - & - & - & - & - & - \\
\hline & SE & 188,136 & 1.0 & $1,670.0$ & 0.060 & 0.961 & 1.027 & 0.138 & 1.546 & 0.070 & 0.045 & 85 & 0.973 \\
\hline & Total & 841,077 & 23.7 & $8,530.7$ & 0.278 & 0.343 & - & - & - & - & 0.072 & 602 & 0.343 \\
\hline \multirow[t]{4}{*}{$1992 / 93$} & NW & 325,648 & 5.0 & $2,299.3$ & 0.217 & 1.428 & 0.712 & 0.156 & 2.000 & 0.083 & 0.305 & 993 & 1.435 \\
\hline & SW & 59,450 & 5.0 & $1,907.4$ & 0.262 & 0.485 & 0.712 & 0.156 & 2.000 & 0.083 & 0.367 & 218 & 0.506 \\
\hline & SE & 210,194 & 4.0 & $2,256.3$ & 0.177 & 0.644 & 0.712 & 0.156 & 2.000 & 0.083 & 0.249 & 523 & 0.653 \\
\hline & Total & 944,113 & 23.0 & $8,124.5$ & 0.283 & 0.482 & - & - & - & - & 0.465 & 4,388 & 0.623 \\
\hline \multirow[t]{5}{*}{$1994 / 95$} & NW & 209,990 & 14.0 & $3,229.4$ & 0.433 & 0.747 & 1.793 & 0.083 & 1.658 & 0.055 & 0.200 & 420 & 0.749 \\
\hline & NE & 314,697 & 26.1 & $2,554.1$ & 1.022 & 0.411 & 1.320 & 0.147 & 2.000 & 0.115 & 0.774 & 2,437 & 0.430 \\
\hline & SW & 39,911 & 41.6 & $2,469.0$ & 1.687 & 0.200 & 1.793 & 0.083 & 1.658 & 0.055 & 0.789 & 315 & 0.210 \\
\hline & $\mathrm{SE}$ & 173,180 & 5.0 & $1,293.0$ & 0.386 & 0.519 & 1.320 & 0.147 & 2.000 & 0.115 & 0.293 & 507 & 0.531 \\
\hline & Total & 737,778 & 86.7 & $9,545.5$ & 0.909 & 0.200 & - & - & - & - & 0.499 & 3,678 & 0.307 \\
\hline \multirow{4}{*}{$1996 / 97$} & $\mathrm{NE}$ & 337,779 & 14.0 & $3,133.4$ & 0.446 & 0.356 & 1.381 & 0.190 & 1.700 & 0.062 & 0.274 & 926 & 0.375 \\
\hline & SW & 53,960 & 17.5 & $3,124.4$ & 0.560 & 0.369 & 1.520 & 0.194 & 1.632 & 0.117 & 0.286 & 162 & 0.394 \\
\hline & SE & 187,983 & 6.0 & $2,098.5$ & 0.286 & 0.500 & 1.381 & 0.190 & 1.700 & 0.062 & 0.176 & 331 & 0.515 \\
\hline & Total & 867,919 & 38.5 & $11,140.9$ & 0.345 & 0.230 & - & - & - & - & 0.170 & 1,474 & 0.274 \\
\hline \multirow[t]{5}{*}{$1998 / 99$} & NW & 314,708 & 2.0 & 997.0 & 0.201 & 0.660 & 0.639 & 0.419 & 1.684 & 0.078 & 0.264 & 832 & 0.786 \\
\hline & $\mathrm{NE}$ & 328,037 & 4.9 & 652.8 & 0.751 & 0.669 & 0.575 & 0.560 & 0.773 & 0.074 & 0.505 & 1,655 & 0.876 \\
\hline & SW & 48,333 & 30.8 & $2,333.5$ & 1.320 & 0.431 & 0.639 & 0.419 & 1.684 & 0.078 & 1.740 & 841 & 0.500 \\
\hline & SE & 25,709 & 34.9 & $1,561.0$ & 2.233 & 0.145 & 1.046 & 0.128 & 1.787 & 0.082 & 1.892 & 504 & 0.167 \\
\hline & Total & 716,787 & 72.6 & $5,544.3$ & 1.309 & 0.202 & - & - & - & - & 0.535 & 3,831 & 0.430 \\
\hline \multirow[t]{5}{*}{$2000 / 01$} & NW & 271,089 & 43.2 & $3,751.9$ & 1.153 & 0.389 & 1.368 & 0.128 & 1.762 & 0.074 & 0.741 & 2,016 & 0.396 \\
\hline & $\mathrm{NE}$ & 348,535 & 44.3 & $3,941.1$ & 1.124 & 0.293 & 1.668 & 0.132 & 1.956 & 0.071 & 0.659 & 2,297 & 0.305 \\
\hline & SW & 79,594 & 30.5 & $3,152.9$ & 0.968 & 0.224 & 0.780 & 0.418 & 1.645 & 0.072 & 1.035 & 815 & 0.362 \\
\hline & $\mathrm{SE}$ & 148,828 & 0.0 & $3,320.2$ & - & - & - & - & - & - & - & - & - \\
\hline & Total & 848,046 & 118.1 & $14,166.1$ & 0.833 & 0.189 & - & - & - & - & 0.605 & 5,128 & 0.215 \\
\hline \multirow[t]{3}{*}{$2002 / 03$} & NW & 266,687 & 12.0 & $2,777.2$ & 0.432 & 0.393 & 1.291 & 0.126 & 1.548 & 0.094 & 0.259 & 691 & 0.404 \\
\hline & $\mathrm{SE}$ & 69,872 & 3.0 & $2,111.9$ & 0.142 & 0.489 & 1.902 & 0.087 & 1.672 & 0.050 & 0.062 & 44 & 0.493 \\
\hline & Total & 760,938 & 91.8 & $12,176.0$ & 0.754 & 0.144 & - & - & - & - & 0.378 & 2,873 & 0.157 \\
\hline \multirow[t]{5}{*}{$2004 / 05$} & NW & 278,281 & 19.5 & 970.0 & 2.015 & 0.780 & 1.688 & 0.199 & 2.050 & 0.075 & 1.223 & 3,405 & 0.791 \\
\hline & $\mathrm{NE}$ & 336,130 & 85.8 & $3,381.8$ & 2.537 & 0.196 & 1.295 & 0.080 & 1.583 & 0.460 & 1.551 & 5,214 & 0.309 \\
\hline & SW & 51,373 & 16.0 & 856.7 & 1.873 & 0.235 & 1.437 & 0.232 & 1.686 & 0.099 & 1.099 & 564 & 0.270 \\
\hline & $\mathrm{SE}$ & 212,181 & 10.0 & $8,158.7$ & 0.123 & 0.575 & 1.295 & 0.080 & 1.583 & 0.460 & 0.075 & 159 & 0.629 \\
\hline & Total & 877,965 & 131.4 & $13,367.2$ & - & - & - & - & - & - & 1.064 & 9,342 & 0.337 \\
\hline
\end{tabular}

(2) $\mathrm{T}=1$ : Dec 15-Jan 15; $\mathrm{T}=\mathbf{2}$ : Jan 16-31; $\mathrm{T}=3$ : Feb $1-$ 15; and $\mathrm{T}=4$ : Feb 16-Mar 15 (Grouping T2)

(3) $\mathrm{T}=1$ : Dec 15-Jan 15; $\mathrm{T}=\mathbf{2}$ : Jan 16-Feb 15; and $\mathrm{T}=3$ : Feb 16-Mar 15 (Grouping T3)

(4) $\mathrm{T}=1:$ Dec; $\mathrm{T}=\mathbf{2}: \mathbf{J a n} ; \mathrm{T}=3:$ Feb; and $\mathrm{T}=4$ : Mar (Grouping T4)

(5) $\mathrm{T}=1$ : Dec and Jan and $\mathrm{T}=2$ : Feb and Mar (Grouping T5)

QAIC (Burnham and Anderson, 1998) rather than AIC was used to select amongst these models and alternatives for specifying $T$ because it can be applied to GLMs with overdispersed Poisson errors. QAIC is defined here as

$$
Q A I C=-\frac{2 \log (L)}{\hat{c}}+2 p
$$

where $L$ is likelihood of the model without over-dispersion, $\hat{c}$ is the estimated over-dispersion parameter and $p$ is the number of estimable parameters including the overdispersion parameter.

\section{RESULTS}

Distribution of humpback whale sightings

Fig. 5 shows the distribution of the primary searching effort (grey lines) and positions of humpback whale primary sightings during the 1987/88-2004/05 JARPA cruises. The primary searching effort covered the research area quite thoroughly. Humpback whales were widely distributed in Areas IV and V, and were more frequently sighted in Area IV. They were rarely found in the Prydz Bay and the Ross Sea, but were observed in southern strata as far south as the ice edge. Estimated densities were highest between $80^{\circ} \mathrm{E}$ and $120^{\circ} \mathrm{E}$ in both the northern and southern strata; this area corresponds to the eastern side of the Kerguelen Plateau. There were relatively few sightings in the longitudinal sector between $130^{\circ} \mathrm{E}$ and $145^{\circ} \mathrm{E}$.

\section{Abundance estimates}

Tables $5 \mathrm{a}$ and $5 \mathrm{~b}$ show abundance estimates $(P)$ of humpback whales in Areas IV and V respectively, by season and stratum. The tables also show the total number of the primary sightings after truncation $(n)$, open ocean area $(A)$, primary searching effort $(L), n / L$, effective search half width $\left(w_{s}\right)$, 


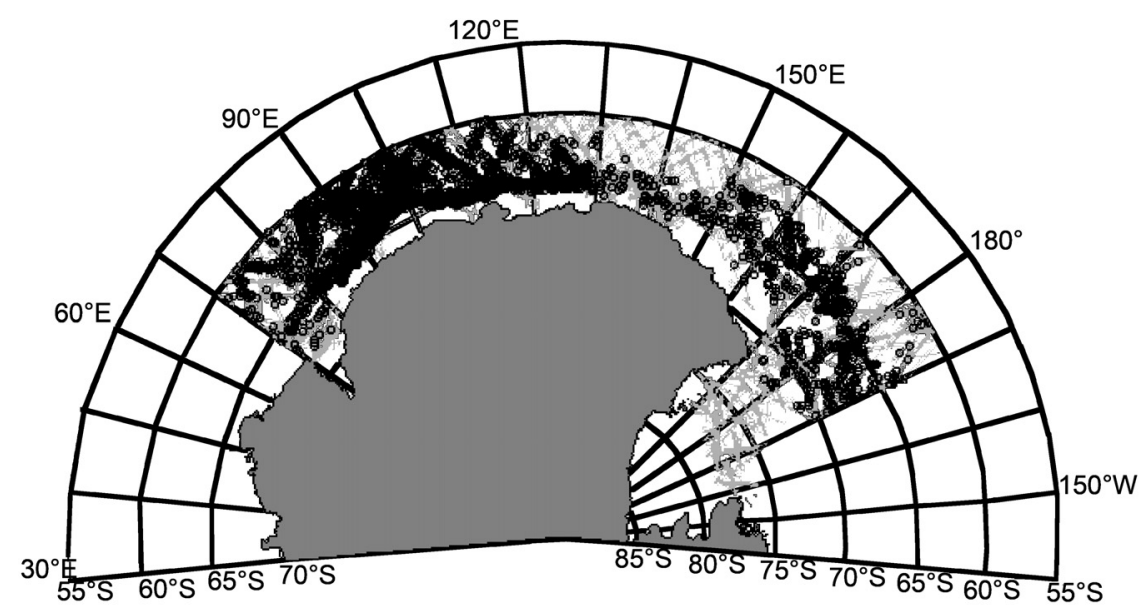

Fig. 5. Distribution of the primary searching effort (grey lines) and associated humpback whale primary sightings during the 1989/90-2004/05 JARPA surveys in Areas IV and V which are used in the analyses of this paper.
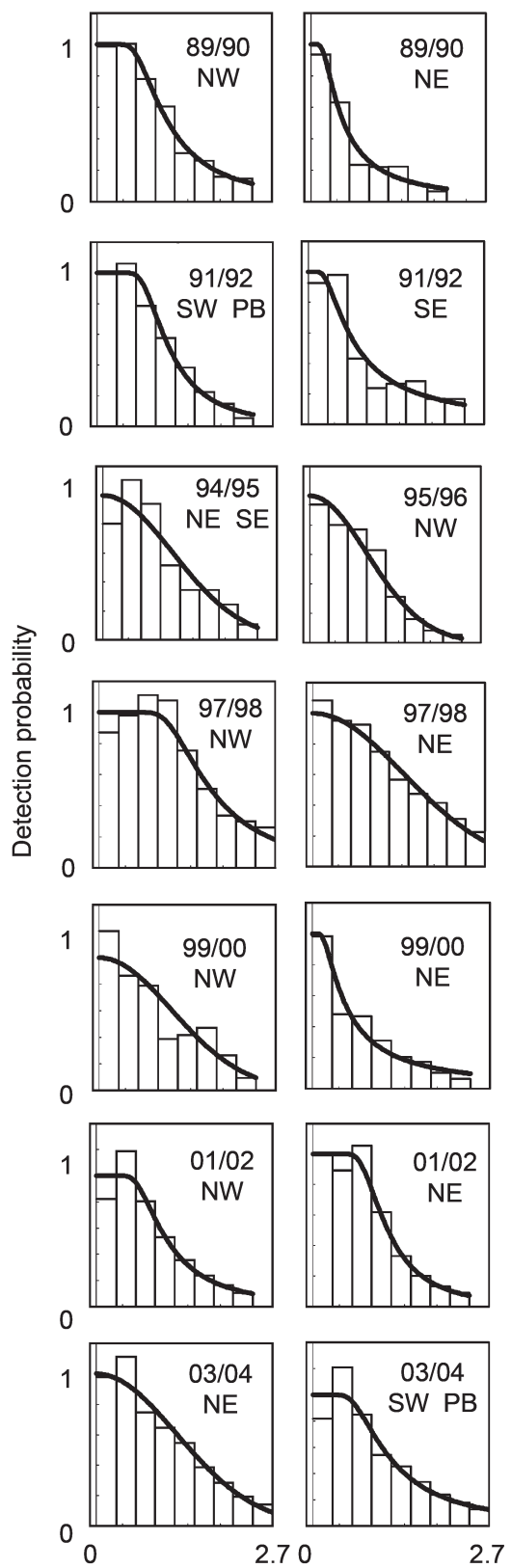
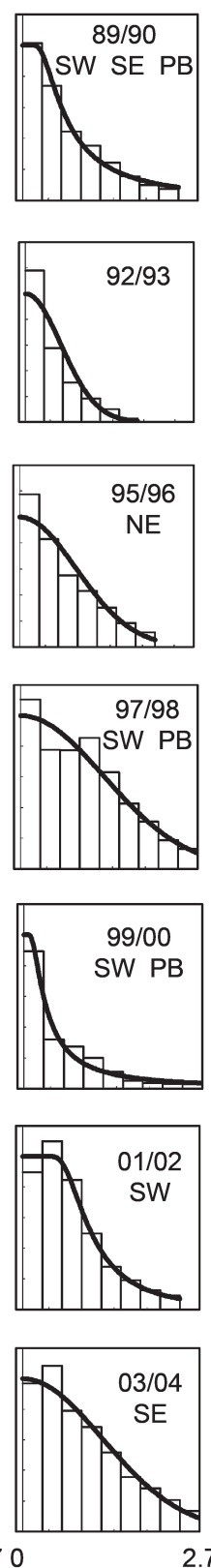
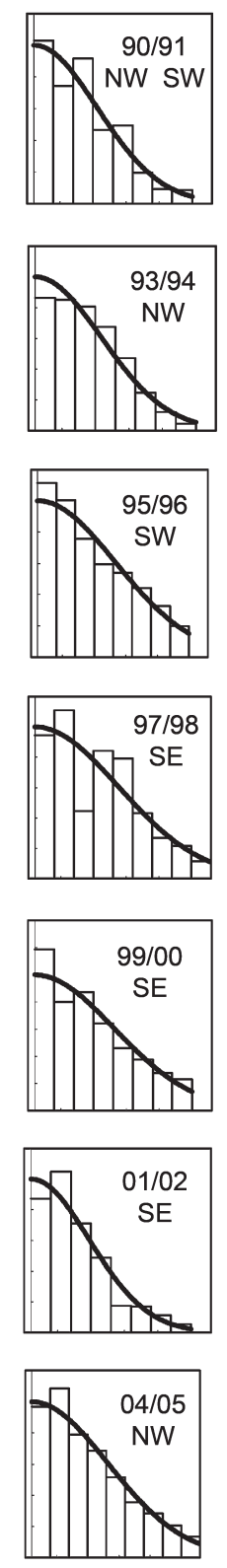

2.70

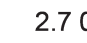

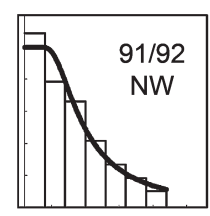
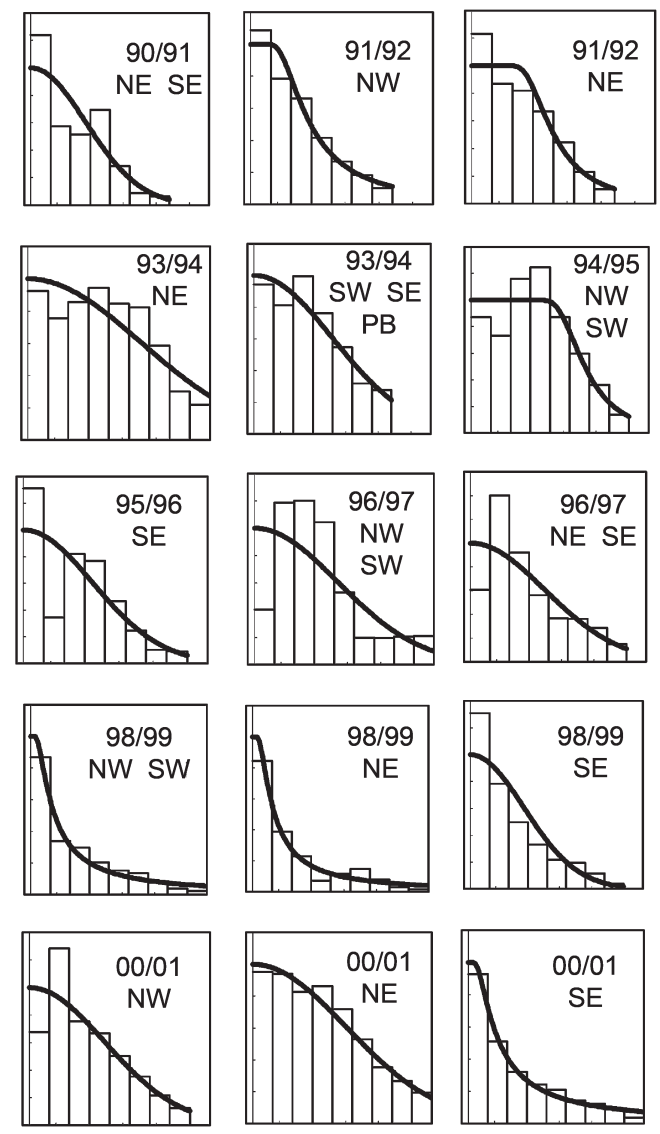

Perpendicular distance
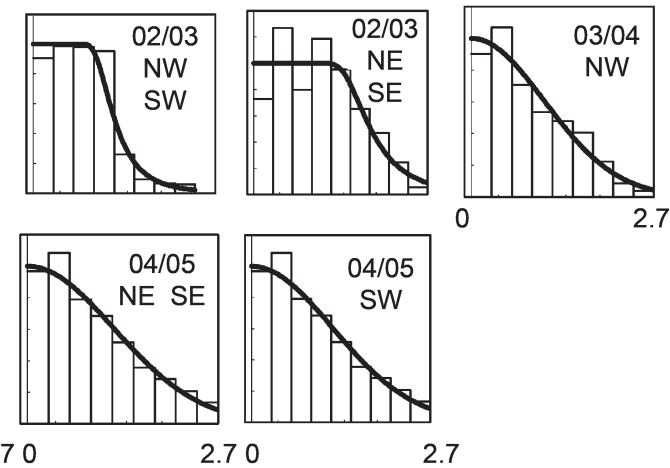

Fig. 6. Estimated detection probability functions (AIC-based selection between hazard rate and half-normal forms) for humpback whales for the $1989 / 90$ to 2004/05 JARPA surveys. These results are for data combined across the SSV, SVC and SVP survey modes. 
estimated mean school size $(E(s))$, estimated whale density (D: whales/100 n.miles ${ }^{2}$ ) and the CVs for each estimate. The primary effort and associated primary sightings of humpback schools whales used for these estimates are plotted in Fig. 1. Abundance estimates in Area IV range from 2,747 (CV = $0.153)$ for the $1993 / 94$ season to $31,134(\mathrm{CV}=0.123)$ for the 2001/02 season (Table 5a). In Area V, abundance estimates range from $1,474(\mathrm{CV}=0.274)$ for the $1996 / 97$ season to $9,342(\mathrm{CV}=0.337)$ for the $2004 / 05$ season (Table $5 \mathrm{~b})$. The most recent abundance estimate for Areas IV (2003/04 season) and $\mathrm{V}(2004 / 05$ season) combined is $37,125(\mathrm{CV}=$ 0.288 , where this computation also takes account of the estimates of additional variance). Fig. 6 shows the detection probability functions in relation to perpendicular distance from the trackline in nautical miles that were used for the analyses by cruise and stratum (or combination of strata); there are no obvious indications of model mis-specification, nor of any trend towards distributions with sharper peaks near the trackline in the earlier years.

\section{Abundance trends}

Fig. 7 shows the abundance estimates in Areas IV and V plotted against survey season; for comparative purposes, estimates obtained using IDCR-SOWER data (Branch, 2011) are also shown. An increasing trend in abundance is evident for both Areas IV and V, more clearly so for the former. Annual rates of increase estimates from the JARPA surveys using equation (5) are $16.4 \%(95 \% \mathrm{CI}=9.5-23.3 \%)$ for Area IV over the $1989 / 90$ to $2003 / 04$ cruises, and $12.1 \%$ (95\% CI $=1.7-22.6 \%$ ) for Area $\mathrm{V}$ over the 1990/91 to 2004/05 cruises. The estimate for Area IV is clearly significantly positive; the result for Area $\mathrm{V}$ is also significantly above zero, but not as clearly so as that for Area IV. The additional CVs are estimated as 0.309 and 0.437 for Areas IV and V respectively (Table 7).

\section{Sensitivity tests}

Alternative estimates of effective search half-width

The effects on abundance estimates at the Area level, and also on annual rates of increase, compared to the base case for these and the following two sets of sensitivity tests are shown in Table $6 \mathrm{a}$ and $6 \mathrm{~b}$, with differences in estimates of precision and the associated additional variance shown in Table 7.

There are occasional instances of a large difference, but viewed overall the average change in the abundance estimates from the base case never exceeds 5\%, and any alteration to the rate of increase estimate is below $1 \%$.

\section{Inclusion of tracklines that followed the contours of the ice edge \\ These tests apply only to Area IV, and are somewhat restricted because of insufficient data to allow them to be conducted for the first four seasons of surveys there. For the subsequent seasons, these alternative treatments make little difference on average to abundance estimates (Table 6a), and also have little impact on the estimated abundance trend (Table 7). Thus there is no definitive indication that including tracklines that followed the contours of the ice edge in estimating humpback whale abundance and trends introduces substantial bias.}

Unsurveyed areas and incomplete coverage

Results for these sensitivity tests mirror those for the use of alternative functional forms to estimate effective search halfwidth: the average change in the abundance estimates from
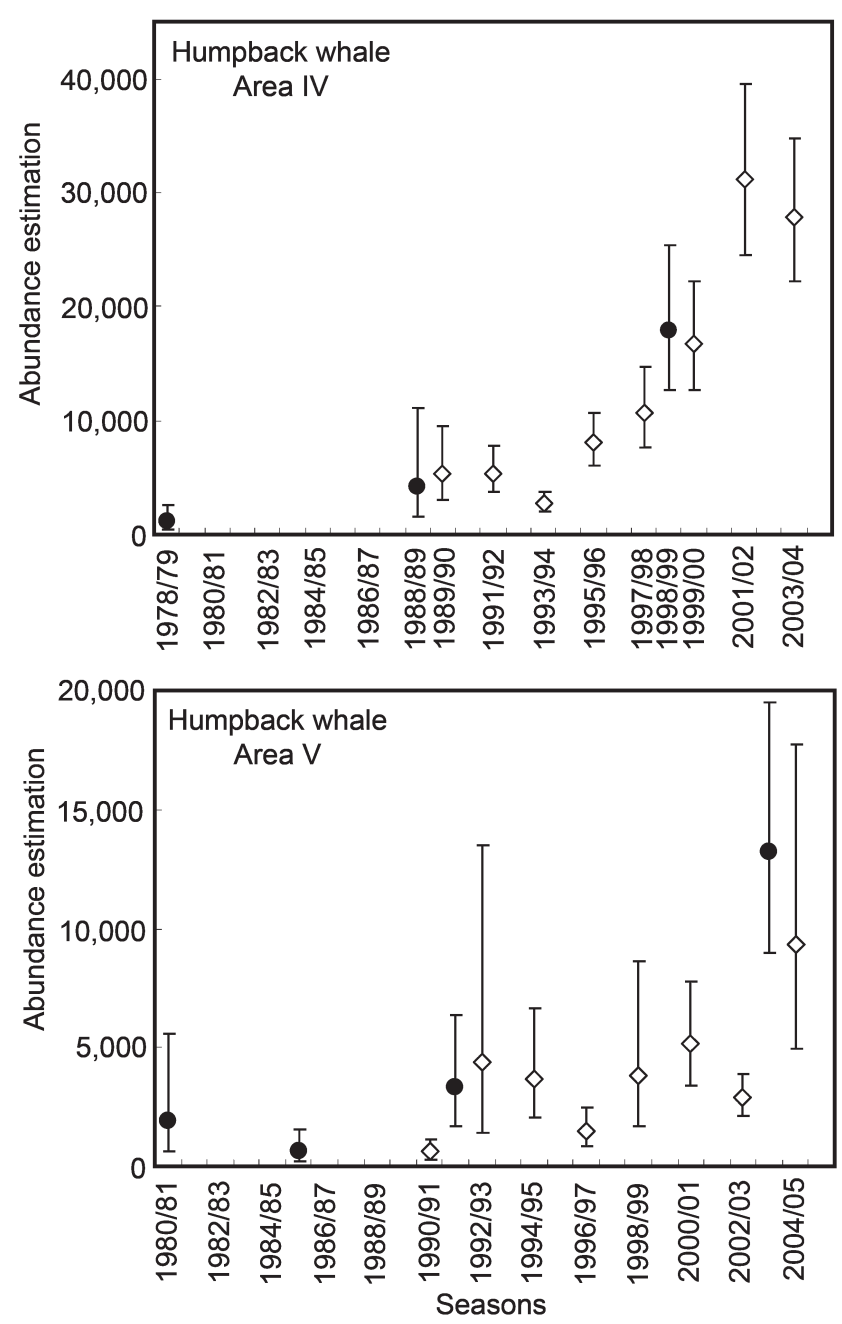

Fig. 7. Abundance estimates for humpback whales in Areas IV and V (south of $60^{\circ} \mathrm{S}$ ), which were surveyed primarily during January to February, from the JARPA surveys from $1988 / 89$ to $2004 / 05$. Estimates from the IDCR-SOWER surveys (Branch, 2011) are shown by the filled circles. Vertical lines show $95 \%$ confidence intervals.

the base case and any alteration in the rate of increase estimate are small (Table 6a, $6 \mathrm{~b}$ and 7 ).

\section{The effect of survey modes and survey timing}

Table 8a shows the observed number of sightings SSV, SVC and SVP surveys, as used for input to the GLM models of equation (6), by season and stratum. Table $8 \mathrm{~b}$ shows the QAIC for each model and estimated instantaneous annual rates of increase for Areas IV and V with their 95\% confidence intervals. Comparison of the abundance trend estimates in Table 6a, shows broad agreement for Area IV - all point estimates are high and in the 16-20\% range. However, this is not the case for Area V, for which most point estimates in Table $8 \mathrm{~b}$ are less than half that for the base case. Nevertheless, all the Table $8 \mathrm{~b}$ estimates fall within the CIs for the corresponding base case estimates in Table 7. QAIC selects the more parsimonious models, choosing only survey mode amongst the covariates considered, and then only for Area IV. This does not necessarily mean that survey timing or the order in which the strata were surveyed has no effect on estimates, but rather that there is insufficient information content in the data to reveal such an effect. For Area IV, even if the (changing) order of surveying strata is taken into account, although the 
Table 6a

Abundance and annual rate of increase (ROI) estimates for Area IV for the base case and sensitivities.

\begin{tabular}{|c|c|c|c|c|c|c|c|c|c|c|c|}
\hline Season & $1989 / 90$ & 1991/92 & 1993/94 & 1995/96 & $1997 / 98$ & 1999/00 & $2001 / 02$ & 2003/04 & $\begin{array}{c}\text { Average } \% \\
\text { of change }\end{array}$ & $\begin{array}{l}\text { ROI } \\
(\%)\end{array}$ & $\begin{array}{l}\text { Change from } \\
\text { base case (\%) }\end{array}$ \\
\hline Base case & $\begin{array}{c}5,325 \\
-\end{array}$ & $\begin{array}{c}5,408 \\
-\end{array}$ & 2,747 & $\begin{array}{c}8,066 \\
-\end{array}$ & $\begin{array}{c}10,657 \\
-\end{array}$ & $\begin{array}{c}16,751 \\
-\end{array}$ & $\begin{array}{c}31,134 \\
-\end{array}$ & $\begin{array}{c}27,783 \\
-\end{array}$ & - & $\begin{array}{c}16.4 \\
-\end{array}$ & - \\
\hline Hazard rate model & $\begin{array}{c}5,325 \\
0 \%\end{array}$ & $\begin{array}{c}5,666 \\
5 \%\end{array}$ & $\begin{array}{l}2,331 \\
-15 \%\end{array}$ & $\begin{array}{c}8,051 \\
0 \%\end{array}$ & $\begin{array}{c}10,537 \\
-1 \%\end{array}$ & $\begin{array}{c}17,233 \\
3 \%\end{array}$ & $\begin{array}{c}31,108 \\
0 \%\end{array}$ & $\begin{array}{c}25,818 \\
-7 \%\end{array}$ & $\begin{array}{c}- \\
-2 \%\end{array}$ & $\begin{array}{c}16.1 \\
-\end{array}$ & $\begin{array}{c}-0.3 \\
-\end{array}$ \\
\hline Half-normal model & $\begin{array}{l}4,041 \\
-24 \%\end{array}$ & $\begin{array}{c}5,183 \\
-4 \%\end{array}$ & $\begin{array}{c}2,747 \\
0 \%\end{array}$ & $\begin{array}{c}8,066 \\
0 \%\end{array}$ & $\begin{array}{c}11,205 \\
5 \%\end{array}$ & $\begin{array}{c}12,632 \\
-25 \%\end{array}$ & $\begin{array}{c}32,844 \\
5 \%\end{array}$ & $\begin{array}{c}27,708 \\
0 \%\end{array}$ & $\begin{array}{c}- \\
-5 \%\end{array}$ & $\begin{array}{c}17.2 \\
-\end{array}$ & $\begin{array}{c}0.8 \\
-\end{array}$ \\
\hline Trackline Option B* & $\begin{array}{c}5,325 \\
-\end{array}$ & $\begin{array}{c}5,408 \\
-\end{array}$ & $\begin{array}{c}2,747 \\
-\end{array}$ & $\begin{array}{c}8,066 \\
-\end{array}$ & $\begin{array}{c}10,705 \\
0 \%\end{array}$ & $\begin{array}{l}14,685 \\
-12 \%\end{array}$ & $\begin{array}{c}30,713 \\
-1 \%\end{array}$ & $\begin{array}{c}29,376 \\
6 \%\end{array}$ & $-2 \%$ & $\begin{array}{c}16.4 \\
-\end{array}$ & $\begin{array}{c}0.0 \\
-\end{array}$ \\
\hline Trackline Option C & $\begin{array}{c}5,325 \\
-\end{array}$ & $\begin{array}{c}5,408 \\
-\end{array}$ & $\begin{array}{c}2,747 \\
-\end{array}$ & $\begin{array}{c}8,066 \\
-\end{array}$ & $\begin{array}{c}11,034 \\
4 \%\end{array}$ & $\begin{array}{c}14,146 \\
-16 \%\end{array}$ & $\begin{array}{c}30,484 \\
-2 \%\end{array}$ & $\begin{array}{c}34,224 \\
23 \%\end{array}$ & $\begin{array}{c}- \\
2 \%\end{array}$ & $\begin{array}{c}17.1 \\
-\end{array}$ & $\begin{array}{c}0.7 \\
-\end{array}$ \\
\hline Gap abundance $=0 * *$ & $\begin{array}{c}5,325 \\
-\end{array}$ & $\begin{array}{c}5,408 \\
-\end{array}$ & $\begin{array}{c}2,747 \\
-\end{array}$ & $\begin{array}{l}7,467 \\
-7 \%\end{array}$ & $\begin{array}{c}10,657 \\
-\end{array}$ & $\begin{array}{c}16,479 \\
-2 \%\end{array}$ & $\begin{array}{c}30,359 \\
-2 \%\end{array}$ & $\begin{array}{c}24,924 \\
-10 \%\end{array}$ & $-5 \%$ & $\begin{array}{c}15.9 \\
-\end{array}$ & $\begin{array}{c}-0.5 \\
-\end{array}$ \\
\hline Gap abundance $=$ stratum below** & $\begin{array}{c}5,325 \\
-\end{array}$ & $\begin{array}{c}5,408 \\
-\end{array}$ & $\begin{array}{c}2,747 \\
-\end{array}$ & $\begin{array}{c}8,578 \\
6 \%\end{array}$ & $\begin{array}{c}10,657 \\
-\end{array}$ & $\begin{array}{c}18,145 \\
8 \%\end{array}$ & $\begin{array}{c}31,730 \\
2 \%\end{array}$ & $\begin{array}{c}31,905 \\
15 \%\end{array}$ & - & $\begin{array}{c}17.2 \\
-\end{array}$ & $\begin{array}{c}0.8 \\
-\end{array}$ \\
\hline Poor coverage corrections*** & $\begin{array}{c}5,325 \\
-\end{array}$ & $\begin{array}{c}5,408 \\
-\end{array}$ & $\begin{array}{c}2,747 \\
-\end{array}$ & $\begin{array}{c}8,279 \\
3 \%\end{array}$ & $\begin{array}{c}10,657 \\
-\end{array}$ & $\begin{array}{c}16,751 \\
-\end{array}$ & $\begin{array}{c}31,134 \\
-\end{array}$ & $\begin{array}{c}27,783 \\
-\end{array}$ & $\begin{array}{c}- \\
3 \%\end{array}$ & $\begin{array}{c}16.4 \\
-\end{array}$ & $\begin{array}{c}0.0 \\
-\end{array}$ \\
\hline
\end{tabular}

*Due to the small number of sightings, there were insufficient data to evaluate options B and C for the 1989/90 to 1995/96 seasons; the averages quoted for these sensitivities refer to the $1997 / 98$ to $2003 / 04$ seasons. ${ }^{* *} 1995 / 96,1999 / 00,2001 / 02$ and 2003/04 seasons. ${ }^{* * *}$ SE stratum in 1995/96 season.

Table 6b

Abundance estimates and annual rates of increase for Area V for the base case and sensitivities.

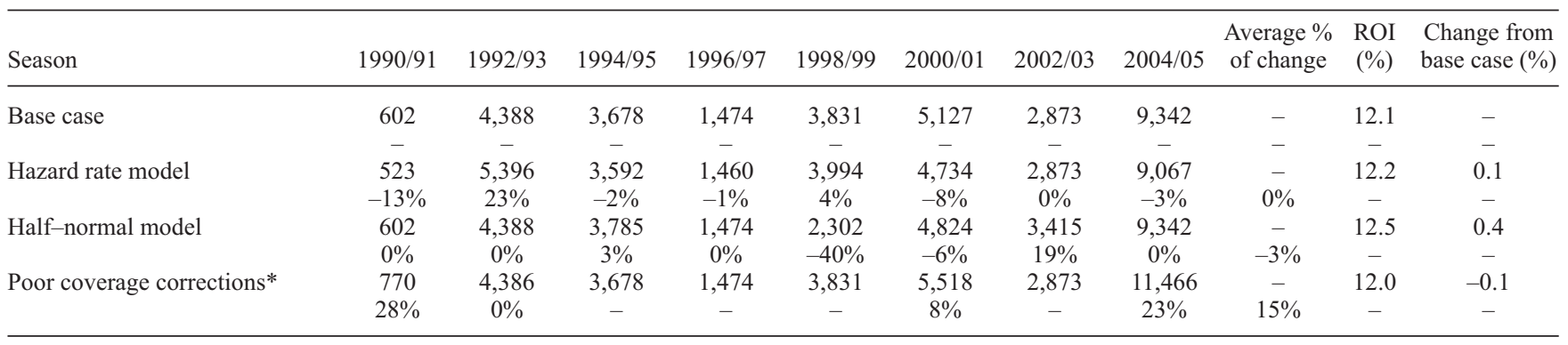

*SE stratum in 1990/91, NE stratum in 1992/93, SE stratum in 2000/01, NW and SW strata in 2004/05 seasons.

Table 7

Estimated annual instantaneous rates of exponential increase, together with their standard errors and $95 \%$ confidence intervals, for base case and other detection function selections for Areas IV and V, respectively. $\alpha$ is the instantaneous rate of increase. $\mathrm{CV}_{\text {add }}$ is the $\mathrm{CV}$ corresponding to the additional variance associated with abundance estimates.

\begin{tabular}{|c|c|c|c|c|c|c|}
\hline & $\alpha$ & $\operatorname{SE}(\alpha)$ & $95 \%$ CILL & $95 \%$ CIUL & $\mathrm{CV}_{\text {add }}$ & $\mathrm{SE}\left(\mathrm{CV}_{\text {add }}\right)$ \\
\hline \multicolumn{7}{|l|}{ Area IV } \\
\hline Base case & 0.164 & 0.028 & 0.095 & 0.233 & 0.309 & 0.102 \\
\hline Hazard rate & 0.161 & 0.033 & 0.082 & 0.241 & 0.374 & 0.114 \\
\hline Half-normal & 0.172 & 0.027 & 0.105 & 0.238 & 0.296 & 0.097 \\
\hline Opt B & 0.164 & 0.028 & 0.096 & 0.233 & 0.304 & 0.102 \\
\hline Opt C & 0.171 & 0.028 & 0.103 & 0.239 & 0.302 & 0.103 \\
\hline Gap abun $=0$ & 0.159 & 0.028 & 0.089 & 0.228 & 0.313 & 0.103 \\
\hline Gap abun=below & 0.172 & 0.028 & 0.103 & 0.241 & 0.306 & 0.103 \\
\hline Poor coverage corrections & 0.164 & 0.028 & 0.095 & 0.233 & 0.309 & 0.102 \\
\hline \multicolumn{7}{|l|}{ Area V } \\
\hline Base case & 0.121 & 0.043 & 0.017 & 0.226 & 0.437 & 0.167 \\
\hline Hazard rate & 0.122 & 0.045 & 0.012 & 0.232 & 0.469 & 0.181 \\
\hline Half-normal & 0.125 & 0.040 & 0.028 & 0.222 & 0.386 & 0.168 \\
\hline Poor coverage corrections & 0.120 & 0.043 & 0.014 & 0.225 & 0.440 & 0.162 \\
\hline
\end{tabular}

best estimate of the rate of increase drops, the lower $95 \%$ confidence limit remains at or above $10 \%$ as for the base case. For Area $\mathrm{V}$ the results in Table $8 \mathrm{~b}$ do barely admit the possibility of no increase within their $95 \%$ CI's, but with one exception, taking survey ordering into account increases estimates of the rate of increase compared to the QAICselected model.

Under QAIC, inclusion of survey mode as a factor is selected only for Area IV, but the change to the estimated rate of increase is negligible, and the mode factor estimates themselves suggest SVC and SSV density estimates only slightly (and not significantly) greater than those for SVP. For Area V, a likely reason for non-selection of these factors, which suggest somewhat lower densities in SVC and SSV modes compared to SVP, is their associated high estimated standard errors. 
Table 8a (part 1)

Observed numbers of sightings (truncated at $2.7 \mathrm{n}$. miles perpendicular distance after smearing) by survey mode used for input to the GLMs of equation (6) in Area IV.

\begin{tabular}{|c|c|c|c|c|c|}
\hline \multicolumn{2}{|c|}{ Area IV by SSV } & \multicolumn{2}{|c|}{ Area IV SVC } & \multicolumn{2}{|c|}{ Area IV SVP } \\
\hline Stratum & $n_{o b s}$ & Stratum & $n_{o b s}$ & Stratum & $n_{\rho b s}$ \\
\hline
\end{tabular}

\begin{tabular}{lr}
\hline $\mathbf{1 9 8 9 / 9 0}$ & \\
$\mathrm{NW}$ & 21.2 \\
$\mathrm{NE}$ & 20.0 \\
$\mathrm{SW}$ & 10.3 \\
$\mathrm{SE}$ & 1.0 \\
$\mathrm{~PB}$ & 2.0
\end{tabular}

\section{1/92}

NW $\quad 42.0$

NE $\quad 16.0$

$\begin{array}{llll}\text { SW } & 13.5 & \text { SW } & 6.8\end{array}$

$\begin{array}{llll}\text { SE } & 9.9 & \text { SE } & 5.7\end{array}$

$\begin{array}{llll}\mathrm{PB} & 0.0 & \mathrm{~PB} & 1.0\end{array}$

1993/94

$\begin{array}{llll}\text { NW } & 33.5 & \text { NW } & 10.0\end{array}$

$\begin{array}{llll}\mathrm{NE} & 16.9 & \mathrm{NE} & 11.0\end{array}$

$\begin{array}{llll}\text { SW } & 17.3 & \text { SW } & 6.9\end{array}$

$\begin{array}{llll}\text { SE } & 6.0 & \text { SE } & 1.0\end{array}$

$\begin{array}{llll}\text { PB } & 3.0 & \text { PB } & 1.0\end{array}$

1995/96

$\begin{array}{llll}\text { NW } & 101.4 & \text { NW } & 20.7\end{array}$

$\begin{array}{llll}\text { NE } & 33.0 & \text { NE } & 13.0 \\ \text { SW } & 34.7 & \text { SW } & 19.6\end{array}$

$\begin{array}{llll}\text { SW } & 34.7 & \text { SW } & 19.6\end{array}$

$\begin{array}{llll}\mathrm{SE} & 20.6 & \mathrm{SE} & 7.0\end{array}$

$\begin{array}{llll}\text { PB } & 0.0 & \text { PB } & 0.0\end{array}$

$1997 / 98$

$\begin{array}{lr}\text { NW } & 149.9 \\ \text { NE } & 80.2 \\ \text { SW } & 129.8 \\ \text { SE } & 17.9 \\ \text { PB } & 2.0\end{array}$

$\begin{array}{lr}\text { NW } & 28.7 \\ \text { NE } & 24.6 \\ \text { SW } & 17.7 \\ \text { SE } & 5.0 \\ \text { PB } & 0.0\end{array}$

$\begin{array}{ll}\text { NW } & 40.6 \\ \text { NE } & 93.9\end{array}$

SW $\quad 76.5$

SE $\quad 86.2$

PB $\quad 0.0$

2001/02

$\begin{array}{ll}\text { NW } & 195.0 \\ \text { NE } & 178.9\end{array}$

SW $\quad 261.1$

SE $\quad 52.3$

PB

0.0

\section{NW}

\section{NE}

SE $\quad 21.3$

PB

0.0

$\begin{array}{lr}\text { NW } & 8.7 \\ \text { NE } & 1.0 \\ \text { SW } & 20.9 \\ \text { SE } & 1.0 \\ \text { PB } & 0.0\end{array}$

2003/04

NW 174.

NE $\quad 198.8$

SW $\quad 293.8$

SE $\quad 280.2$

PB

0.0

$\begin{array}{ll}\text { NW } & 16.0 \\ \text { NE } & 18.0\end{array}$

SW 29.9

SE $\quad 1.0$

PB

0.0

NW $\quad 33.0$

NE $\quad 27.7$

SW $\quad 31.7$

SE $\quad 38.8$

$\begin{array}{lr}\mathrm{PB} & 1.0\end{array}$

$\begin{array}{lr}\text { NW } & 10.0 \\ \text { NE } & 43.0 \\ \text { SW } & 21.4 \\ \text { SE } & 58.0 \\ \text { PB } & 3.0\end{array}$

NW $\quad 41.0$

NE $\quad 40.0$

SW $\quad 96.6$

SE $\quad 10.0$

PB $\quad 0.0$

NW $\quad 33.0$

NE $\quad 52.6$

SW $\quad 64.3$

SE $\quad 128.3$

PB $\quad 1.0$

\section{DISCUSSION}

\section{Distribution of humpback whales}

Humpback whales were widely distributed in Areas IV and $\mathrm{V}$, with higher concentrations in Area IV, although they were rarely found in Prydz Bay and the Ross Sea. There were relatively few sightings in the longitudinal sector from $130^{\circ} \mathrm{E}$ to $145^{\circ} \mathrm{E}$, which coincides with a gap in krill distribution (Murase et al., 2006). However, the development of a quantitative approach to the comparison of humpback whale distribution to krill distribution and oceanographic features in the research area is beyond the scope of the present paper. It will be investigated in the future.
Table 8a (part 2)

Observed numbers of sightings (truncated at $2.7 \mathrm{n}$. miles perpendicular distance after smearing) by survey mode used for input to the GLMs of equation (6) in Area V.

\begin{tabular}{|c|c|c|c|c|c|}
\hline \multicolumn{2}{|c|}{ Area V by SSV } & \multicolumn{2}{|c|}{ Area V SVC } & \multicolumn{2}{|c|}{ Area V SVP } \\
\hline Stratum & $n_{o b s}$ & Stratum & $n_{o b s}$ & Stratum & $n_{o b s}$ \\
\hline \multicolumn{6}{|l|}{$1990 / 91$} \\
\hline NW & 1.0 & & & & \\
\hline $\mathrm{NE}$ & 1.0 & & & & \\
\hline SW & 21.7 & & & & \\
\hline $\mathrm{SE}$ & 1.0 & & & & \\
\hline \multicolumn{6}{|l|}{$1992 / 93$} \\
\hline NW & 5.0 & NW & 0.0 & & \\
\hline $\mathrm{NE}$ & 3.0 & $\mathrm{NE}$ & 6.0 & & \\
\hline SW & 1.0 & SW & 4.0 & & \\
\hline SE & 3.0 & SE & 1.0 & & \\
\hline \multicolumn{6}{|l|}{$1994 / 95$} \\
\hline NW & 6.0 & NW & 8.0 & & \\
\hline $\mathrm{NE}$ & 10.0 & $\mathrm{NE}$ & 17.0 & & \\
\hline SW & 26.6 & SW & 15.0 & & \\
\hline SE & 3.0 & SE & 2.0 & & \\
\hline \multicolumn{6}{|l|}{$1996 / 97$} \\
\hline NW & 1.0 & NW & 0.0 & & \\
\hline $\mathrm{NE}$ & 12.9 & $\mathrm{NE}$ & 1.0 & & \\
\hline SW & 8.0 & SW & 8.6 & & \\
\hline $\mathrm{SE}$ & 6.0 & SE & 0.0 & & \\
\hline \multicolumn{6}{|l|}{ 1998/99 } \\
\hline NW & 2.8 & NW & 4.7 & NW & 3.6 \\
\hline $\mathrm{NE}$ & 16.8 & $\mathrm{NE}$ & 4.5 & $\mathrm{NE}$ & 0.0 \\
\hline SW & 15.6 & SW & 3.0 & SW & 11.7 \\
\hline SE & 30.1 & SE & 0.0 & SE & 4.0 \\
\hline \multicolumn{6}{|l|}{ 2000/01 } \\
\hline NW & 29.3 & NW & 5.0 & NW & 8.9 \\
\hline $\mathrm{NE}$ & 23.6 & $\mathrm{NE}$ & 8.0 & $\mathrm{NE}$ & 12.2 \\
\hline SW & 11.8 & SW & 3.6 & SW & 14.9 \\
\hline SE & 0.0 & SE & 0.0 & SE & 0.0 \\
\hline \multicolumn{6}{|l|}{$2002 / 03$} \\
\hline NW & 6.0 & NW & 1.0 & NW & 5.0 \\
\hline $\mathrm{NE}$ & 39.6 & $\mathrm{NE}$ & 3.0 & $\mathrm{NE}$ & 14.9 \\
\hline SW & 15.0 & SW & 1.6 & SW & 2.0 \\
\hline $\mathrm{SE}$ & 2.0 & SE & 0.0 & SE & 1.0 \\
\hline \multicolumn{6}{|l|}{$2004 / 05$} \\
\hline NW & 8.6 & NW & 5.7 & NW & 5.0 \\
\hline $\mathrm{NE}$ & 46.0 & $\mathrm{NE}$ & 7.2 & $\mathrm{NE}$ & 22.8 \\
\hline SW & 15.0 & SW & 0.0 & SW & 2.0 \\
\hline SE & 9.0 & SE & 0.0 & SE & 1.0 \\
\hline
\end{tabular}

\section{Abundance estimates and abundance trend based on JARPA data}

As noted earlier, the IWC Scientific Committee has made several suggestions to improve abundance estimation of Antarctic minke (and by inference humpback) whales from JARPA surveys during previous meetings, particularly at the recent review Workshop (IWC, 2008). Table 1 shows the recommended work by the workshop and how these suggestions have been addressed in the analyses of this paper. It shows that all high priority items have been considered as have most medium priority items. We believe that these few remaining medium priority items seem unlikely to greatly effect the estimates of abundance and trend presented here, although they will be considered in the future.

Although the information content of the data to determine inter-mode differences is poor, the results of sensitivity analyses undertaken here provide no basis to question the pooling of the data across survey modes (SSV, SVC and SVP) for the base case abundance estimation. The same conclusion follows for the effect of including data from 
Table $8 \mathrm{~b}$

QAIC and estimated annual instantaneous rate of exponential increase in Areas IV and V. is the estimated over-dispersion parameter. The line in bold indicates the model selected by QAIC.

\begin{tabular}{|c|c|c|c|c|c|c|c|}
\hline Model & $\hat{c}$ & QAIC & $\Delta \mathrm{QAIC}$ & $\alpha$ & $\operatorname{SE}(\alpha)$ & $\alpha 95 \% \mathrm{LL}$ & $\alpha 95 \% \mathrm{UL}$ \\
\hline \multicolumn{8}{|l|}{ Area IV } \\
\hline (i) & 13.76 & 119.89 & 1.03 & 0.199 & 0.017 & 0.166 & 0.233 \\
\hline (ii) & 14.35 & 118.86 & 0.00 & 0.201 & 0.018 & 0.165 & 0.237 \\
\hline (iii) with T1 & 14.44 & 124.05 & 5.19 & 0.199 & 0.019 & 0.161 & 0.237 \\
\hline (iii) with $\mathrm{T} 2$ & 14.24 & 121.85 & 2.99 & 0.203 & 0.018 & 0.166 & 0.239 \\
\hline (iii) with T3 & 14.20 & 120.29 & 1.42 & 0.202 & 0.018 & 0.166 & 0.238 \\
\hline (iii) with $\mathrm{T} 4$ & 14.14 & 123.03 & 4.17 & 0.195 & 0.018 & 0.159 & 0.231 \\
\hline (iii) with T5 & 14.10 & 121.01 & 2.15 & 0.201 & 0.018 & 0.165 & 0.236 \\
\hline (iv) with T1 & 13.72 & 140.11 & 21.25 & 0.159 & 0.029 & 0.101 & 0.218 \\
\hline (iv) with T2 & 13.46 & 138.06 & 19.20 & 0.159 & 0.029 & 0.101 & 0.217 \\
\hline (iv) with T3 & 13.28 & 131.34 & 12.47 & 0.176 & 0.025 & 0.127 & 0.225 \\
\hline (iv) with T4 & 13.63 & 163.61 & 44.75 & 0.172 & 0.021 & 0.130 & 0.215 \\
\hline (iv) with T5 & 13.68 & 127.65 & 8.78 & 0.177 & 0.021 & 0.135 & 0.219 \\
\hline \multicolumn{8}{|l|}{ Area V } \\
\hline (i) & 11.08 & 78.29 & 0.00 & 0.066 & 0.034 & -0.001 & 0.134 \\
\hline (ii) & 10.58 & 82.25 & 3.96 & 0.056 & 0.035 & -0.015 & 0.126 \\
\hline (iii) with $\mathrm{T} 1$ & 9.24 & 97.91 & 19.62 & 0.050 & 0.036 & -0.022 & 0.122 \\
\hline (iii) with $\mathrm{T} 2$ & 9.89 & 90.89 & 12.60 & 0.046 & 0.035 & -0.023 & 0.116 \\
\hline (iii) with T3 & 9.82 & 89.44 & 11.15 & 0.045 & 0.035 & -0.024 & 0.115 \\
\hline (iii) with T4 & 9.01 & 96.03 & 17.74 & 0.054 & 0.035 & -0.016 & 0.124 \\
\hline (iii) with T5 & 10.85 & 82.57 & 4.28 & 0.057 & 0.037 & -0.016 & 0.130 \\
\hline (iv) with T1 & 4.97 & 138.14 & 59.86 & 0.167 & 0.053 & 0.061 & 0.273 \\
\hline (iv) with T2 & 5.21 & 131.09 & 52.80 & 0.161 & 0.050 & 0.061 & 0.261 \\
\hline (iv) with $\mathrm{T} 3$ & 5.77 & 118.01 & 39.72 & 0.158 & 0.051 & 0.056 & 0.260 \\
\hline (iv) with T4 & 7.24 & 112.24 & 33.95 & 0.088 & 0.046 & -0.004 & 0.180 \\
\hline (iv) with T5 & 10.07 & 91.96 & 13.68 & 0.062 & 0.048 & -0.034 & 0.158 \\
\hline
\end{tabular}

tracklines that followed the contours of the ice edge in the analyses. The impacts on overall estimates of abundance and trend of the choice of functional form for the detection function, and of some instances of survey gaps and poor coverage, are small.

The greater differences between the base case and GLM estimates of rates of increase for Area V than for Area IV is not altogether surprising. It is readily evident from inspection of Fig. 7 that while the data for Area IV give broadly consistent indications of a steady increase, for Area $\mathrm{V}$ the estimate from the final 2004/5 survey is highly influential in determining any point estimate for rate of increase (a feature also of the IDCR-SOWER results for this Area). The point estimates themselves are high given the estimate of Clapham et al. (2006) of a maximum demographically plausible annual increase rate for humpback whales of $10.6 \%$. However, it should be noted that the lower 95\% CIs for this rate for the base case and sensitivities in Table 7 are all below this bound, although only barely so for some cases. The possibility of immigration and changes in distribution (see Conclusion) warrants further investigation.

\section{Comparison with IDCR-SOWER estimates}

A comparison of the list of JARPA and IDCR-SOWER estimates of abundance in Table 9a, and the corresponding plot in Fig. 7, shows the results from the two sets of surveys to be entirely consistent.

The rates of increase in Areas IV and V, as estimated from JARPA and IDCR-SOWER results are also similar (Table 9b). Rates of increase estimated from JARPA data are 16.4\% $(95 \% \mathrm{CI}=9.5-23.3 \%)$ in Area IV and $12.1 \%(95 \% \mathrm{CI}=1.7-$ $22.6 \%$ ) in Area $\mathrm{V}$, which compare with rates estimated from IDCR-SOWER data of $14.9 \%(95 \% \mathrm{CI}=10.0-19.7 \%)$ and $12.8 \%(95 \%$ CI $=8.7-16.9 \%)$ for those two Areas respectively (Branch, 2011). However Branch's estimates of precision are based on estimates of additional variance of zero. Importantly the greater frequency of the JARPA surveys makes realistic (and reasonably precise - Table 7) estimates of additional variance achievable - something that is scarcely possible for the lesser numbers of IDCR-SOWER surveys, and this has important implications for reliable estimation of precision. If the estimates determined in this paper are used, although the IDCR-SOWER estimates change only slightly, their CIs do expand (Table 9b). They

Table 9a

Comparison of JARPA and IDCR-SOWER (Branch, 2011) abundance estimates of humpback whales in Areas IV and V.

\begin{tabular}{|c|c|c|c|c|}
\hline \multirow[b]{2}{*}{ Season } & \multicolumn{2}{|c|}{ JARPA } & \multicolumn{2}{|c|}{ IDCR/SOWER } \\
\hline & Estimate & $\mathrm{CV}$ & Estimate & $\mathrm{CV}$ \\
\hline \multicolumn{5}{|l|}{ Area IV } \\
\hline $1978 / 79$ & - & - & 1,102 & 0.46 \\
\hline $1988 / 89$ & - & - & 4,167 & 0.53 \\
\hline $1989 / 90$ & 5,325 & 0.302 & - & - \\
\hline $1991 / 92$ & 5,408 & 0.188 & - & - \\
\hline $1993 / 94$ & 2,747 & 0.153 & - & - \\
\hline $1995 / 96$ & 8,066 & 0.142 & - & - \\
\hline $1997 / 98$ & 10,657 & 0.166 & - & - \\
\hline $1998 / 99$ & - & - & 17,938 & 0.18 \\
\hline $1999 / 00$ & 16,751 & 0.143 & - & - \\
\hline $2001 / 02$ & 31,134 & 0.123 & - & - \\
\hline 2003/04 & 27,783 & 0.115 & - & - \\
\hline \multicolumn{5}{|l|}{ Area V } \\
\hline $1980 / 81$ & - & - & 1,876 & 0.60 \\
\hline $1985 / 86$ & - & - & 622 & 0.50 \\
\hline 1990/91 & 602 & 0.343 & - & - \\
\hline $1991 / 92$ & - & - & 3,310 & 0.34 \\
\hline $1992 / 93$ & 4,388 & 0.623 & - & - \\
\hline $1994 / 95$ & 3,678 & 0.307 & - & - \\
\hline $1996 / 97$ & 1,474 & 0.274 & - & - \\
\hline $1998 / 99$ & 3,831 & 0.430 & - & - \\
\hline $2000 / 01$ & 5,127 & 0.215 & - & - \\
\hline $2002 / 03$ & 2,873 & 0.157 & - & - \\
\hline $2003 / 04$ & - & - & 13,246 & 0.20 \\
\hline $2004 / 05$ & 9,342 & 0.337 & - & - \\
\hline
\end{tabular}


Table 9b

Comparison of JARPA and IDCR-SOWER (Branch, 2008) rates of increase estimates in Areas IV and V. The values marked IDCR-SOWER are as estimated by Branch (2008), whose estimates of $\mathrm{CV}_{\text {add }}$ were zero for both these Areas; those marked IDCR-SOWER revise Branch's results by incorporating the base case estimates of $\mathrm{CV}_{\text {add }}$ obtained for each of these Areas from the analyses in this paper (see Table 7).

\begin{tabular}{lcccc}
\hline Programme & Period $(\mathrm{D} / \mathrm{M} / \mathrm{Y})$ & Estimate & 95\%CILL & 95\%CIUL \\
\hline Area IV & & & & \\
JARPA & $31 / 12 / 89-01 / 03 / 04$ & 0.164 & 0.095 & 0.233 \\
IDCR-SOWER & $28 / 12 / 78-22 / 02 / 99$ & 0.148 & 0.081 & 0.215 \\
Area V & & & & \\
JARPA & $01 / 11 / 91-08 / 03 / 05$ & 0.121 & 0.017 & 0.226 \\
IDCR-SOWER & $17 / 12 / 80 /-28 / 02 / 04$ & 0.122 & 0.053 & 0.191 \\
\hline
\end{tabular}

nevertheless still reflect somewhat greater precision than do the JARPA estimates. The reason for this is that the IDCRSOWER surveys extend over a longer period of time.

\section{Comparison with western and eastern Australia estimates}

The abundance estimate of humpback whales off western Australia based on an aerial survey conducted in 2005 is 13,145 (95\% CI = 4,984-38,726 - Paxton et al., 2011). The annual rate of increase for this population has been estimated at $10.15 \%(\mathrm{SE}=4.6 \%$, see Bannister and Hedley, 2001). Off eastern Australia the abundance estimate based on data collected in 2004 is 7,090 $(\mathrm{SE}=660)$ and the rate of increase is estimated at $10.6 \%(\mathrm{SE}=0.5 \%)($ Noad et al., 2011$)$. These quite high estimates of rates of increase are consistent among surveys conducted in breeding areas and migratory corridors and those carried out in Antarctic feeding areas (IDCRSOWER and JARPA).

Estimates of abundance in absolute terms off western and eastern Australia are lower than the estimates for Antarctic Areas IV and V. One possible explanation is that the surveys at low latitudes are conducted in specific migratory corridors which may not cover all the adults migrating. Furthermore, recent studies conducted in the Western Antarctic Peninsula region (McKay et al., 2004) and in the North Atlantic (Smith et al., 1999) have suggested that some portions of humpback population do not return to their breeding grounds every year. The possibility of sex-biased migration to breeding grounds has been suggested (Jenner et al., 2006), which also would imply that surveys in migratory corridors do not cover complete populations; this warrants further investigation. Therefore the lesser abundance estimates in lower latitude surveys off western and eastern Australia compared with those obtained for the Antarctic feeding grounds of Areas IV and $\mathrm{V}$ do not necessarily indicate inconsistency.

\section{CONCLUSION}

In summary, humpback whales in Area IV are increasing at an apparently high rate. Although there is also an increase indicated for Area V, it is neither as rapid nor as precisely estimated. Given that coastal surveys indicate that Breeding Stocks D and E are both increasing at an annual rate of about $10 \%$, which is close to the maximum possible demographically, the greater rates of increase (from both the JARPA and IDCR-SOWER surveys) estimated for the Area IV feeding grounds compared to Area V may reflect a distributional shift of the increasing numbers of Breeding Stock E humpbacks towards Area IV, perhaps to take advantage of higher concentrations of krill there.

\section{ACKNOWLEDGEMENTS}

We wish to express our gratitude to Doug Butterworth and anonymous reviewers for their constructive suggestions to improve a previous version of this paper. Our gratitude also to Luis A. Pastene and Toshihide Kitakado for their help in the preparation of this paper. We thank all researchers, captains, officers and crew members participating in the JARPA surveys. We also thank Seiji Ohsumi, Hiroshi Hatanaka and Yoshihiro Fujise for useful comments on the analyses, Trevor Branch and Susan Johnston in the provision of some information, and also Atsushi Wada, Shoko Ohkawa and Tomoko Hasegawa for their help with figures.

\section{REFERENCES}

Allen, K.R. 1980. Conservation and Management of Whales. University of Washington Press, Seattle and Butterworth and Co., London. ix +110 pp. Bannister, J.L. and Hedley, S.L. 2001. Southern Hemisphere group IV humpback whales: their status from recent aerial survey. Mem. Queensl. Mus. 47(2): 587-98.

Branch, T.A. 2011. Humpback whale abundance south of $60^{\circ} \mathrm{S}$ from three complete circumpolar sets of surveys. J. Cetacean Res. Manage. (special issue 3): 53-69.

Branch, T.A. and Butterworth, D.S. 2001a. Estimates of abundance south of $60^{\circ} \mathrm{S}$ for cetacean species sighted frequently on the $1978 / 79$ to $1997 / 98$ IWC/IDCR-SOWER sighting surveys. J. Cetacean Res. Manage. 3(3): 251-70.

Branch, T.A. and Butterworth, D.S. 2001b. Southern Hemisphere minke whales: standardised abundance estimates from the 1978/79 to $1997 / 98$ IDCR-SOWER surveys. J. Cetacean Res. Manage. 3(2): 143-74.

Branch, T.A., Matsuoka, K. and Miyashita, T. 2004. Evidence for increases in Antarctic blue whales based on Bayesian modelling. Mar. Mammal Sci. 20(4): 726-54.

Buckland, S.T., Anderson, D.R., Burnham, K.P., Laake, J.L., Borchers, D.L. and Thomas, L. 2001. Introduction to Distance Sampling: Estimating Abundance of Biological Populations. Oxford University Press, Oxford, UK. vi $+\mathrm{xv}+432 \mathrm{pp}$

Buckland, S.T. and Anganuzzi, A.A. 1988. Comparison of smearing methods in the analysis of minke sightings data from IWC/IDCR Antarctic cruises. Rep. int. Whal. Commn 38: 257-63.

Burnham, K.P. and Anderson, D.R. 1998. Model Selection and Inference. A Practical Information-Theoretic Approach. Springer-Verlag, New York. 353pp.

Clapham, P., Wade, P. and Zerbini, A. 2006. Plausible rates of population growth in humpback whales revisited. Paper SC/58/SH4 presented to the IWC Scientific Committee, May 2006, St. Kitts and Nevis, West Indies (unpublished). 12pp. [Paper available from the Office of this Journal]

Government of Japan. 1987. The research plan for the feasibility study on 'The program for research on the Southern Hemisphere minke whale and for preliminary research on the marine ecosystem in the Antarctic'. Paper SC/D87/1 presented to the IWC Scientific Committee Special Meeting to Consider the Japanese Research Permit (Feasibility Study), Cambridge, December 1987 (unpublished). 36pp. [Paper available from the Office of this Journal]

Government of Japan. 1996. The 1996/97 research plan for the Japanese Whale Research Program under Special Permit in the Antarctic. Paper SC/48/SH3 presented to IWC Scientific Committee, June 1996, Aberdeen (unpublished). 11pp plus addendum. [Paper available from the Office of this Journal].

Hakamada, T., Matsuoka, K. and Nishiwaki, N. 2006. An update of Antarctic minke whale abundance estimate based on JARPA data. Pape SC/D06/J6 presented to the JARPA Review Workshop, Tokyo, 4-8 December 2006 (unpublished). 34pp plus addendum. [Paper available from the Office of this Journal].

Hakamada, T., Matsuoka, K. and Nishiwaki, S. 2007. Improvements of the JARPA abundance estimation of Antarctic minke whales based on JARPA Review Meeting recommendations. Paper SC/59/IA11 presented to the IWC Scientific Committee, May 2007, Anchorage, USA (unpublished). $24 \mathrm{pp}$. [Paper available from the Office of this Journal].

International Whaling Commission. 2005. Report of the Scientific Committee. Annex H. Report of the sub-committee on other Southern Hemisphere whale stocks. J. Cetacean Res. Manage. (Suppl.) 7:235-44. International Whaling Commission. 2008. Report of the Intersessional Workshop to Review Data and Results from Special Permit Research on Minke Whales in the Antarctic, Tokyo, 4-8 December 2006. J. Cetacean Res. Manage. (Suppl.) 10:411-45. 
International Whaling Commission. 2009. Report of the Scientific Committee. Annex H. Report of the sub-committee on other Southern Hemisphere whale stocks. J. Cetacean Res. Manage. (Suppl.) 11:22047.

Jackson, J., Zerbini, A., Clapham, P., Constantine, R., Garrigue, C., Hauser, N., Poole, M. and Baker, C.S. 2008. Progress on a two-stock catch allocation model for reconstructing population histories of east Australia and Oceania. Paper SC/60/SH14 presented to the IWC Scientific Committee, June 2008, Santiago, Chile (unpublished). 12pp. [Paper available from the Office of this Journal].

Jenner, K.C.S., Jenner, M.N., Salgado Kent, C.P. and Brasseur, M. 2006. A preliminary analysis of sampling biases of sex ratio from two seasons of biopsy samples for breeding stock D. Paper SC/A06/HW20 presented to the IWC Workshop on Comprehensive Assessment of Southern Hemisphere Humpback Whales, Hobart, Tasmania, 3-7 April 2006 (unpublished). 6pp. [Paper available from the Office of this Journal].

Johnston, S.E., Zerbini, A.N. and Butterworth, D.S. 2011. A Bayesian approach to assess the status of Southern Hemisphere humpback whales (Megaptera novaeangliae) with an application to breeding stock G. J. Cetacean Res. Manage. (special issue 3): 309-317.

Johnston, S.J. and Butterworth, D.S. 2005. A Bayesian assessment of the west and east Australian breeding populations (stocks D and E) of Southern Hemisphere humpback whales. Paper SC/57/SH15 presented to the IWC Scientific Committee, June 2005, Ulsan, Korea (unpublished). $25 \mathrm{pp}$. [Paper available from the Office of this Journal].

Johnston, S.J. and Butterworth, D.S. 2007. Corrected assessment results for the Southern Hemisphere humpback whale breeding stocks D and G. Paper SC/59/SH2 presented to the IWC Scientific Committee, May 2007, Anchorage, USA (unpublished). 5pp. [Paper available from the Office of this Journal].

Kasamatsu, F., Joyce, G.G., Ensor, P. and Mermoz, J. 1996. Current occurrence of baleen whales in Antarctic waters. Rep. int. Whal. Commn 46: 293-304.

Kasamatsu, F., Matsuoka, K. and Hakamada, T. 2000. Interspecific relationships in density among the whale community in the Antarctic. Polar Biol. 23: 466-73.

Matsuoka, K., Ensor, P., Hakamada, T., Shimada, H., Nishiwaki, S., Kasamatsu, F. and Kato, H. 2001. Overview of the minke whale sighting survey in IWC/IDCR and SOWER Antarctic cruises from 1978/79 to 2000/01. Paper SC/53/IA6 presented to the IWC Scientific Committee, July 2001, London (unpublished). 75pp. [Paper available from the Office of this Journal].

Matsuoka, K., Ensor, P., Hakamada, T., Shimada, H., Nishiwaki, S., Kasamatsu, F. and Kato, H. 2003. Overview of minke whale sightings surveys conducted on IWC/IDCR and SOWER Antarctic cruises from 1978/79 to 2000/01. J. Cetacean Res. Manage. 5(2): 173-201.

Matsuoka, K., Hakamada, T., Kiwada, H., Murase, H. and Nishiwaki, S. 2005a. Abundance increases of large baleen whales in the Antarctic based on the sighting survey during Japanese Whale Research Program (JARPA). Glob. Environ. Res. 9(2): 105-15.

Matsuoka, K., Hakamada, T., Kiwada, H., Murase, H. and Nishiwaki, S. 2006. Distribution and standardized abundance estimates of humpback, fin and blue whales in the Antarctic Areas IIIE, IV, V and VIW $\left(35^{\circ} \mathrm{E}-145^{\circ} \mathrm{W}\right)$ south of $60^{\circ} \mathrm{S}$. Paper SC/D06/J7 presented to the Intersessional Workshop to Review Data and Results from Special Permit Research on Minke Whales in the Antarctic, Tokyo, 4-8 December
2006 (unpublished). 37pp. [Paper available from the Office of this Journal].

Matsuoka, K., Hakamada, T., Kiwada, H., Nishiwaki, S. and Ohsumi, S. 2005b. Distribution and abundance of sperm whales in the Antarctic Areas IIIE, IV, V and VIW $\left(35^{\circ} \mathrm{E}-145^{\circ} \mathrm{W}\right)$. Paper A\&D7 presented to the Cachalot Assessment Research Planning (CARP) workshop, Marine Biological Laboratory, Swope Center, Woods Hole, MA, 1-3 March 2005

McKay, S., Sirovic, A., Thiele, D., Abery, N.W., Chester, E.T., Hildebrand, J., Wiggins, S., Moore, S. and McDonald, M. 2004. Combining acoustic, sighting survey and sea ice data to investigate the seasonal presence of humpback whales, (Megaptera novaengliae), in the Western Antarctic Peninsula. Paper SC/56/E26 presented to the IWC Scientific Committee, July 2004, Sorrento, Italy (unpublished). 9pp. [Paper available from the Office of this Journal].

Murase, H., Kiwada, H., Matsuoka, K. and Nishiwaki, S. 2006. Results of the cetacean prey survey using echo sounder in JARPA from 1998/99 to 2004/2005. Paper SC/D06/J21 presented to the JARPA Review workshop, Tokyo, 4-8 December 2006 (unpublished). 15pp. [Paper available from the Office of this Journal].

Nishiwaki, S., Ishikawa, H. and Fujise, Y. 2006. Review of general methodology and survey procedure under the JARPA. Paper SC/D06/J2 presented to the JARPA Review Workshop, Tokyo, 4-8 December 2006 (unpublished). 47pp. [Paper available from the Office of this Journal].

Noad, M.J., Dunlop, R.A., Paton, D. and Cato, D.H. 2011. Absolute and relative abundance estimates of Australian east coast humpback whales (Megaptera novaeangliae). J. Cetacean Res. Manage. (special issue 3): 243-252.

Paxton, C.G.M., Hedley, S.L. and Bannister, J.L. 2011. Group IV humpback whales: their status from aerial and land-based surveys off Western Australia, 2005. J. Cetacean Res. Manage. (special issue 3): 223-234.

Smith, T.D., Allen, J., Clapham, P.J., Hammond, P.S., Katona, S., Larsen, F., Lien, J., Mattila, D., Palsbøll, P.J., Sigurjónsson, J., Stevick, P.T. and Øien, N. 1999. An ocean-basin-wide mark-recapture study of the North Atlantic humpback whale (Megaptera novaeangliae). Mar. Mammal Sci. 15(1): 1-32.

Thomas, L., Laake, J.L., Strindberg, S., Marques, F.F.C., Buckland, S.T., Borchers, D.L., Anderson, D.R., Burnham, K.P., Hedley, S.L. and Pollard, J.H. 2002. Distance 4.0. Release 2. Research Unit for Wildlife Population Assessment, University of St Andrews, UK. [Available from: http://www.ruwpa.st-and.ac.uk/distance/].

Thomas, L., Laake, J.L., Strindberg, S., Marques, F.F.C., Buckland, S.T., Borchers, D.L., Anderson, D.R., Burnham, K.P., Hedley, S.L., Pollard, J.H., Bishop, J.R.B. and Marques, T.A. 2005. Distance 5.0. Beta 5. Research Unit for Wildlife Population Assessment, University of St Andrews, UK. [Available from: http://www.ruwpa.st-and.ac.uk/ distance/].

Wade, P.R. 2008. Report of the Intersessional Workshop to Review Data and Results from Special Permit Research on Minke Whales in the Antarctic, Tokyo, 4-8 December 2006. Annex F. A review of the coverage of strata and the sequence of surveys relative to the ice edge during JARPA. J. Cetacean Res. Manage. (Suppl.) 10: 442-44.

Zerbini, A.N., Ward, E., Kinas, P.G., Engel, M. and Andriolo, A. 2011. A Bayesian assessment of the conservation status of humpback whales (Megaptera novaeangliae) in the western South Atlantic Ocean (Breeding Stock A). J. Cetacean Res. Manage. (special issue 3): 131-144. 